\title{
Perspectives on Environmental Barrier Coatings (EBCs) Manufactured via Air Plasma Spray (APS) on Ceramic Matrix Composites (CMCs): A Tutorial Paper
}

\author{
Kang N. Lee ${ }^{1} \cdot$ Dongming Zhu $^{1} \cdot$ Rogerio S. Lima ${ }^{2}$
}

Submitted: 11 September 2020/in revised form: 7 January 2021/Accepted: 8 January 2021 / Published online: 9 February 2021 (C) ASM International 2021

\begin{abstract}
There are many sets of information in the literature (e.g., papers, books and websites) about the great achievements that are expected for aerospace gas turbine engines by the employment of ceramic matrix composites (CMCs) and thermally sprayed environmental barrier coatings (EBCs) in their hot zones (e.g., combustion chambers, vanes, shrouds, blades and afterburners). Among these achievements, it is typically highlighted (i) turbine weight reduction, (ii) reduced fuel consumption, (iii) higher operation temperatures, (iv) superior thrust-toweight ratio and (v) lower emission of toxic gases to the atmosphere. Although these achievements are true, they are generally not well-explained to the reader on how together they come to be. In addition, according to "conventional wisdom", some of these engineering feats are in fact opposing each other (e.g., higher operation temperatures versus lower emissions). The objective of this tutorial paper is to present the reader how these feats are achieved by the concomitant combination of imaginative engineering. It will explain the non-stop driving force for increasing combustion temperatures; show the basic concepts of
\end{abstract}

This article is an invited paper. The authors were invited based on their experience, knowledge, and expertise in this area to provide expert perspectives on a subject relevant to thermal spray. The views expressed in the paper are those of the author(s).

Dr Dongming Zhu passed away May 30, 2018.

Rogerio S. Lima

rogerio.lima@cnrc-nrc.gc.ca

1 National Aeronautics and Space Administration (NASA), 21000 Brookpark Rd., Cleveland, OH 44135, USA

2 National Research Council of Canada (NRC), 75 de Mortagne Blvd., Boucherville, QC J4B 6Y4, Canada
CMCs, the paramount need of EBCs, and the complexity of creating EBC architectures via air plasma spray (APS). Finally, highlights on how EBCs/CMCs are tested at high temperature will be provided. The content of this paper shall be understood by anyone with basic knowledge in materials processing and surface engineering.

Keywords air plasma spray (APS) - ceramic matrix composites (CMCs) · environmental barrier coatings (EBCs) $\cdot$ gas turbine engines $\cdot$ oxide-oxide $\mathrm{CMC} \cdot \mathrm{SiC} / \mathrm{SiC}$ $\mathrm{CMC}$

\section{Introduction}

\section{Overall Concept}

From a materials engineering point-of-view, the combined application of environmental barrier coatings (EBCs) and ceramic matrix composites (CMCs) will be the greatest disruptive technology for enabling the manufacturing of ceramic-based gas turbines. The driving force behind this technology is found on the non-stoppable demand for more efficient and environmentally friendly propulsion and energy generation systems (Spitsberg and Steibel (Ref 1) and Padture (Ref 2)). Those are key society requirements in the $21^{\text {st }}$ century.

EBCs and CMCs are now slowly being introduced as parts of the components located in hot zones (sections) of aerospace gas turbines. These components include the combustion chambers and shrouds. In the future, it is expected that nozzles, blades and afterburners will also be manufactured from CMCs. These turbine parts today are made of high temperature Ni-based metallic super-alloys and protected against high temperature and environment by 
a $\mathrm{ZrO}_{2}-7-8 \mathrm{wt} . \% \mathrm{Y}_{2} \mathrm{O}_{3}$ (YSZ) thermal barrier coating (TBC). CMCs will replace the Ni-based super-alloys as the structural material of gas turbines on the hot zones, whereas EBCs will protect CMCs against environment and high temperature. In a "simplistic" way, it can be stated that EBCs are for CMCs what YSZ TBCs are for Ni-based super-alloys components currently operating on the current gas turbine engines.

EBCs/CMCs are already causing a revolution in the manufacturing and performance of gas turbines. They are allowing turbines to reach power levels not attainable today, by allowing them to operate at higher combustion temperatures simply not achievable by the current technology. Counter-intuitively to the "conventional wisdom", which tells that higher combustion temperatures mean higher emissions of pollutants; these ceramic-based gas turbines will (in fact) emit lower pollutant levels than those of current gas turbines. Finally, due to the fact that CMCs exhibit $\sim 1 / 3$ of the density of Ni-based metallic superalloys, the combination of higher power levels and lower total mass, will result in gas turbines exhibiting superior thrust-to-weight ratios totally unmatched by the current technology. This will be paramount in aerospace applications.

The next sections will explain the basic concepts of this technology and why it is important for aircraft performance, energy generation and the environment.

\section{Basic Concepts on CMCs}

It is widely recognized that monolithic structural ceramicbased materials (e.g., $\mathrm{SiC}, \mathrm{Al}_{2} \mathrm{O}_{3}, \mathrm{Si}_{3} \mathrm{~N}_{4}, \mathrm{TiO}_{2}$ and $\mathrm{ZrO}_{2}$ ) typically exhibit higher values of mechanical strength at high temperatures than those of Ni-based metals. However, they lack "high" toughness to be employed in applications where thermo-mechanical cycling is present. Thermo-mechanical cycling generates stresses (i.e., mechanical loading) in the structure of the materials, which monolithic ceramics cannot easily accommodate. Due to their lack of toughness, they tend to exhibit uncontrollable crack growth (initiated from the ceramic's inherent structural defects) and catastrophic failure upon thermo-mechanical loading. Thermal cycle stress is an event naturally present in gas turbines, mainly in the aerospace ones. Therefore, their application as structural parts in the hot zones of gas turbines is hindered.

The answer for applying ceramic materials in the hot zones of turbine engines is found in CMCs. CMC systems consist of ceramic fibers embedded in a ceramic matrix. A scanning electron microscope (SEM) picture of a polished cross section of a CMC is shown in Fig. 1.

The matrix and fibers are typically made of the same ceramic material. CMCs exhibit the high mechanical

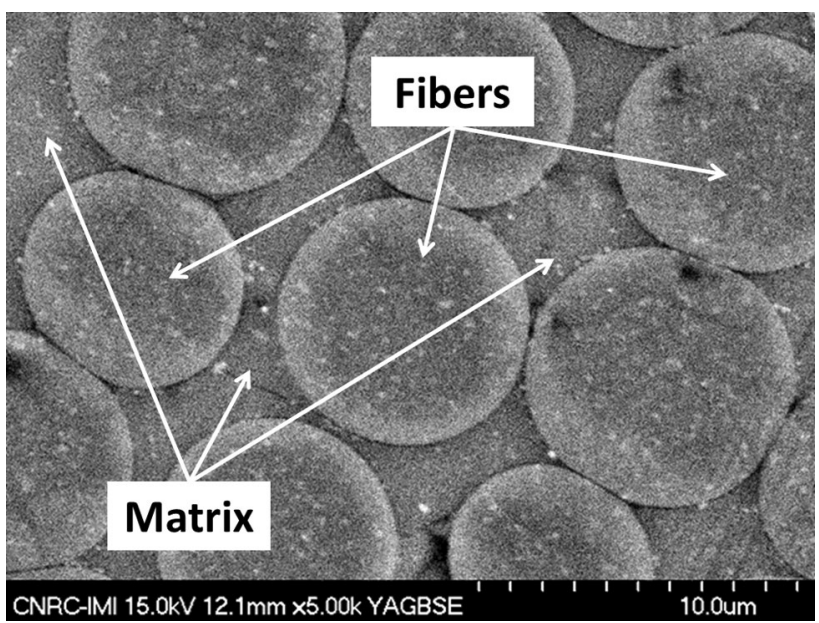

Fig. 1 SEM picture of a polished cross-section of a CMC

strength of monolithic ceramic materials at high temperatures, in addition to the indispensable high fracture toughness. The high toughness of CMCs works via the mechanisms of debonding and sliding, as described by Evans and Marshall (Ref 3). Under the application of a mechanical or thermo-mechanical load, the ceramic matrix cracks from its inherent pre-existing flaws, after its maximum elongation limit is reached. The embedded fibers in the matrix bridge these cracks. To allow crack bridging by the fibers, debonding at the fibre/matrix interface must occur. Therefore, the "weakest link" needs to be found at fibre/matrix interface. By engineering this structure, the matrix can microscopically slide along the bridging fibers, thereby keeping intact the overall CMC macro-structure.

After the localized debonding at the fibre/matrix interface, the matrix can microscopically slide along the bridging fibers, thereby keeping intact the overall CMC macro-structure. This is the key mechanism to avoid catastrophic failure and promote high toughness in CMCs (Ref 3).

There are different CMCs being tested today for gas turbine applications. The one that seems most promising so far is the SiC-based CMC consisting of $\mathrm{SiC}$ fibers embedded in a $\mathrm{SiC}$ matrix (a.k.a., $\mathrm{SiC} / \mathrm{SiC} \mathrm{CMC}$ ), although oxide-based or oxide-oxide CMCs, typically consisting of alumina $\left(\mathrm{Al}_{2} \mathrm{O}_{3}\right)$ and/or mullite $\left(\mathrm{Al}_{6} \mathrm{Si}_{2} \mathrm{O}_{13}\right)$ are also being considered, as highlighted by Dever et al (Ref 4). The strength values of $\mathrm{SiC} / \mathrm{SiC} \mathrm{CMCs}$, oxide-oxide CMCs and $\mathrm{Ni}$-based metallic super-alloys at different temperatures are highlighted in Table 1 (Ref 4). It is possible to notice the superior high temperature performance of the CMCs over the Ni-based super-alloys, mainly regarding the $\mathrm{SiC} / \mathrm{SiC}$ one.

Another great advantage of $\mathrm{CMCs}$ in relation to $\mathrm{Ni}$ based super-alloys is their lower density values. This is critical for aerospace applications, where there is an 
Table $1500 \mathrm{~h}$ rupture strength values in air of SiC/SiC CMCs, oxide-oxide CMCs and Ni-based metallic super-alloys at different temperatures (Ref 4)

\begin{tabular}{lccc}
\hline Testing Temperature, ${ }^{\circ} \mathrm{C}$ & $\begin{array}{c}\text { Ni-based super-alloys } \\
500 \text { h rupture strength in air, MPa }\end{array}$ & $\begin{array}{c}\text { Oxide-oxide CMCs } \\
500 \text { h rupture strength in air, MPa }\end{array}$ & $\begin{array}{c}\text { SiC/SiC CMCs } \\
\text { 500 h rupture strength in air, MPa }\end{array}$ \\
\hline 1100 & $\sim 90$ & $\sim 150$ & $\sim 150$ \\
1200 & Material failure & $\sim 30$ & $\sim 130$ \\
1300 & Material failure & Material failure & $\sim 115$ \\
\hline
\end{tabular}

Table 2 Density values for CMC materials and Ni-based superalloys

\begin{tabular}{lc}
\hline \multicolumn{1}{c}{ Material } & Density, $\mathrm{g} / \mathrm{cm}^{3}$ \\
\hline Ni-based super-alloys & $\sim 8.5$ \\
$\mathrm{SiC} / \mathrm{SiC} \mathrm{CMCs}$ & $\sim 2.6$ \\
$\mathrm{Al}_{2} \mathrm{O}_{3}$ and $\mathrm{Al}_{6} \mathrm{Si}_{2} \mathrm{O}_{13}$ (mullite) oxide-oxide CMCs & $\sim 2.7$ \\
\hline
\end{tabular}

insatiable demand for lighter materials. Table 2 shows that the density values of CMCs are about $1 / 3$ that of Ni-based super-alloys. Therefore, the weight reduction is significant, which for sure will have an important contribution in aircraft performance.

Although CMCs exhibit significant improvements regarding higher operational temperature capabilities and lower density values than those of Ni-based super-alloys, there is an important drawback. At high temperatures in the presence of oxygen, the exposed $\mathrm{SiC} / \mathrm{SiC} \mathrm{CMC}$ surface will oxidize and form a thin silica $\left(\mathrm{SiO}_{2}\right)$ scale, which can be represented by the following formula; e.g.: $\mathrm{SiC}(\mathrm{s})+2 \mathrm{O}_{2}(\mathrm{~g}) \rightarrow \mathrm{SiO}_{2}(\mathrm{~s})+\mathrm{CO}_{2}(\mathrm{~g})$. This is expected and this thin scale does not cause any harm to the CMC structure. However, when a hydrocarbon fuel (e.g., kerosene- $-\mathrm{C}_{\mathrm{x}} \mathrm{H}_{\mathrm{y}}$ ) combusts inside the hot zone of the turbine engine, water vapor is generated as a sub product of the combustion; $\quad$ e.g.: $\quad \mathrm{C}_{\mathrm{x}} \mathrm{H}_{\mathrm{y}}+\mathrm{O}_{2}(\mathrm{~g}) \rightarrow \mathrm{Heat}+\mathrm{H}_{2}$ $\mathrm{O}(\mathrm{g})+\mathrm{CO}_{2}(\mathrm{~g})$. At high combustion temperatures the water vapor reacts with the thin silica layer, generating silicon hydroxide gas, e.g., $\quad \mathrm{SiO}_{2}(\mathrm{~s})+2 \mathrm{H}_{2-}$ $\mathrm{O}(\mathrm{g}) \rightarrow \mathrm{Si}(\mathrm{OH})_{4}(\mathrm{~g})$. Therefore, the $\mathrm{SiC} / \mathrm{SiC}$ CMC structure is corroded by the presence of water vapor, as described by Opila et al (Ref 5). This process is continuous, while combustion occurs, generating material defects, until the complete loss of structural integrity and catastrophic failure of the CMC structure. This same water vapor corrosion attack occurs with oxide-oxide $\mathrm{CMCs}$, as pointed out by Braue and Mechnich (Ref 6). For an $\mathrm{Al}_{2} \mathrm{O}_{3}$-based $\mathrm{CMC}$ the water vapor reacts with $\mathrm{Al}_{2} \mathrm{O}_{3}$, generating aluminum hydroxide gas, e.g., $\quad \mathrm{Al}_{2} \mathrm{O}_{3}(\mathrm{~s})+3 \mathrm{H}_{2}$ $\mathrm{O}(\mathrm{g}) \rightarrow 2 \mathrm{Al}(\mathrm{OH})_{3}(\mathrm{~g})$. The formation of volatile
$\mathrm{Si}(\mathrm{OH})_{4}(\mathrm{~g})$ is also observed in mullite $\left(\mathrm{Al}_{6} \mathrm{Si}_{2} \mathrm{O}_{13}\right)$ containing CMCs.

For this reason, the protection against high-temperature water vapor attack is a critical issue regarding the longterm stability of CMCs. The solution for this problem is currently addressed by the so-called EBCs.

On a brief note, the advantage of $\mathrm{SiC} / \mathrm{SiC} \mathrm{CMCs}$ over oxide-oxide ones is based on the fact that oxide-oxide CMCs cannot operate in temperatures higher than $1200{ }^{\circ} \mathrm{C}$, whereas this limit for $\mathrm{SiC} / \mathrm{SiC} \mathrm{CMCs}$ is typically $1300{ }^{\circ} \mathrm{C}$ (Table 1). On the other hand, oxide-oxide CMCs are of easier high temperature manufacturing because they are already "oxidized"; therefore, they are more affordable in terms of cost. Finally, although both types of CMCs are attacked by water vapor at high temperatures, the attack is more severe for $\mathrm{SiC} / \mathrm{SiC}$ CMCs.

\section{Basic Concepts on EBCs}

As previously stated, EBCs will protect the CMCs against high temperature and environment. Their main function is to protect the structural CMC material against high-temperature water vapor attack and subsequent corrosion, as described in the previous section. The volatilization of the materials present in the CMC structure (due to water vapor attack) results in recession and structural failure. Therefore, one key barrier against the application of CMCs in the hot section structural components of gas turbines is their lack of environmental durability (Lee et al (Ref 7)). In addition to water vapor attack, EBCs will also be subjected to different types of chemical and structural damage. These failure mechanisms and materials' requirements will be discussed in more details in the further sections of this manuscript.

Thermal spray processing, more specifically air plasma spray (APS), is the main manufacturing technique to engineer EBCs. This is related to the overall processing conditions, as well as, its known track record in the gas turbine industry. Other techniques can also be employed. The manufacturing of EBCs will be discussed further in this manuscript. 
Due to the fact the EBCs are still in constant and rapid development, with new materials being frequently tested and many confidentiality issues involved, it is difficult to pin-point the exact standard "state-of-the-art" EBC for $\mathrm{SiC} / \mathrm{SiC}$ CMCs. However, the modern generation of EBCs described in the ongoing open literature for $\mathrm{SiC} / \mathrm{SiC} \mathrm{CMCs}$ is generally based on a tri-layer system: (i) a silicon bond coat (BC) layer, (ii) a mullite $\left(\mathrm{Al}_{6} \mathrm{Si}_{2} \mathrm{O}_{13}\right)$ interlayer and (iii) a rare earth (RE) silicate top layer; as described by $\mathrm{Xu}$ et al (Ref 8).

The $\sim 100-\mu \mathrm{m}$ thick Si BC layer is typically dense and exhibits an excellent chemical and bonding compatibility with the $\mathrm{SiC} / \mathrm{SiC} \mathrm{CMC}$ surface. Moreover, its CTE value is close to that of the $\mathrm{SiC} / \mathrm{SiC} \mathrm{CMCs}$. It also protects the $\mathrm{CMC}$ against oxidation and volatilization. In addition, the $\mathrm{Si} \mathrm{BC}$ provides the necessary surface roughness for mechanical and structural anchoring when the subsequent mullite interlayer is deposited via APS.

The $\sim 100-\mu \mathrm{m}$ thick mullite inter-layer typically serves as a chemical barrier between the Si BC and the RE silicate top layer to avoid potential chemical reactions that would induce damage in the EBC structure (e.g., formation of a low melting point phase). It also protects the Si BC against oxidation. In addition, mullite is a known low thermal conductivity and refractory material, which possess highthermal shock resistance. It also exhibits a "moderate-togood" resistance against water vapor attack. Moreover, just like for the $\mathrm{Si} \mathrm{BC}$, the mullite CTE value is close to that of the $\mathrm{SiC} / \mathrm{SiC} \mathrm{CMCs}$.

The $\sim 100-\mu \mathrm{m}$ thick RE silicate top layer is the main defense against the volatilization of the CMC. There are two types of RE silicate: RE monosilicate $\left(\mathrm{RE}_{2} \mathrm{SiO}_{5}\right)$ and $\mathrm{RE}$ disilicate $\left(\mathrm{RE}_{2} \mathrm{Si}_{2} \mathrm{O}_{7}\right)$. Both exhibit (i) excellent resistance against water vapor attack at high temperature and (ii) low thermal conductivity. Y, Yb, Lu and Sc disilicates have CTE values similar to that of the SiC/SiC CMC, while all RE monosilicates have CTE values higher than the $\mathrm{SiC} /$ $\mathrm{SiC}$ CMC. RE monosilicates are also chemically incompatible with $\mathrm{Si} \mathrm{BC}$ because $\mathrm{RE}$ monosilicates react with silica to form $\mathrm{RE}$ disilicates, i.e., $\mathrm{RE}_{2} \mathrm{SiO}_{5}+\mathrm{SiO}_{2}=-$ $\mathrm{RE}_{2} \mathrm{Si}_{2} \mathrm{O}_{7}$. Mullite inter-layer, therefore, serves as a chemical barrier as well as a CTE transition layer for RE monosilicates top coat. It needs to be highlighted that RE disilicates are chemically compatible and have a good CTE match with $\mathrm{Si} \mathrm{BC}$. For this reason, the $\mathrm{Si} / \mathrm{Yb}$ disilicate twolayer EBC architecture without the mullite inter-layer performs well at high temperatures.

Regarding oxide-oxide CMCs, one single EBC layer is typically employed to protect the substrate against the high temperature environment. The EBC layer is generally alumina $\left(\mathrm{Al}_{2} \mathrm{O}_{3}\right)$, mullite $\left(\mathrm{Al}_{6} \mathrm{Si}_{2} \mathrm{O}_{13}\right)$ or yttria $\left(\mathrm{Y}_{2} \mathrm{O}_{3}\right)$, which are deposited via APS or even flame-spray. These materials are known for their good thermal shock resistance, low thermal conductivity and CTE values similar to those of oxide-oxide CMCs. In addition, these oxidebased EBCs exhibit good chemical bonding with oxideoxide CMCs. It is important to highlight that these EBCs do not exhibit the excellent water vapor attack resistance levels as those of RE silicates. However, as highlighted in Table 2, oxide-oxide CMCs are more suitable for applications at lower temperature conditions than those of $\mathrm{SiC} /$ SiC CMCs. Therefore, they may provide "enough" water vapor attack resistance for this specific application. The main function of EBCs for oxide-oxide CMCs, therefore, is to act as a thermal protection system (TPS). At high service temperatures, oxide-oxide CMCs are subject to creep deformation, resulting in loss of strength and damage tolerance (Steinhauser et al (Ref 9)). Oxide-based EBCs with the thickness ranging from $200 \mu \mathrm{m}$ up to $1000 \mu \mathrm{m}$ have been reported by Mechnich and Braue (Ref 10). They are generally porous and non-gas-tight, which collaborates in reducing their thermal conductivity values, thereby leading to lower temperatures at the CMC. Consequently, the primary function of oxide-based EBCs for oxide-oxide CMCs is the protection against thermal overload, while the secondary function is the protection against water vapor attack. For this reason, this manuscript will be concentrated on thermally sprayed EBCs for SiC/SiC CMCs; although some considerations on EBCs for oxide-oxide CMCs will be provided.

\section{The Driving Force behind EBCs/CMCs}

In order to better understand the driving force behind the use EBCs/CMCs in gas turbines, it is necessary to be aware of the information provided by Figures 2 and 3. Figure 2(a) shows evolution and estimation of the turbine inlet temperature (TIT) (a.k.a., combustion chamber outlet temperature) and the temperature capability of hot zone structural materials from 1960s up to 2030s, based on the sets of data provided by Padture (Ref 2) and Clarke et al (Ref 11). It is possible to see that the introduction of TBCs, in addition to film cooling, allowed an important jump in the combustion temperatures since the 1980s. However, this steady increase has not been maintained. Since the 2010s the TITs are plateauing after reaching levels of $\sim 1500{ }^{\circ} \mathrm{C}$. For example, the modern 10,000 kgf thrust Rolls-Royce EJ200 engine that is the power plant for the Typhoon jet fighter has a maximum TIT of $1530{ }^{\circ} \mathrm{C}$, according to Farokhi (Ref 12). One of the key reasons for this plateauing trend resides on the fact that the maximum temperature capability limit of Ni-based alloys have been essentially reached, which is $\sim 1000{ }^{\circ} \mathrm{C}$ (Fig. 2(a)).

The need for the continuing increase in the turbine inlet temperatures can be explained by looking at Fig. 2(b), which is a plot adapted from Perepezko (Ref 13). The plot 

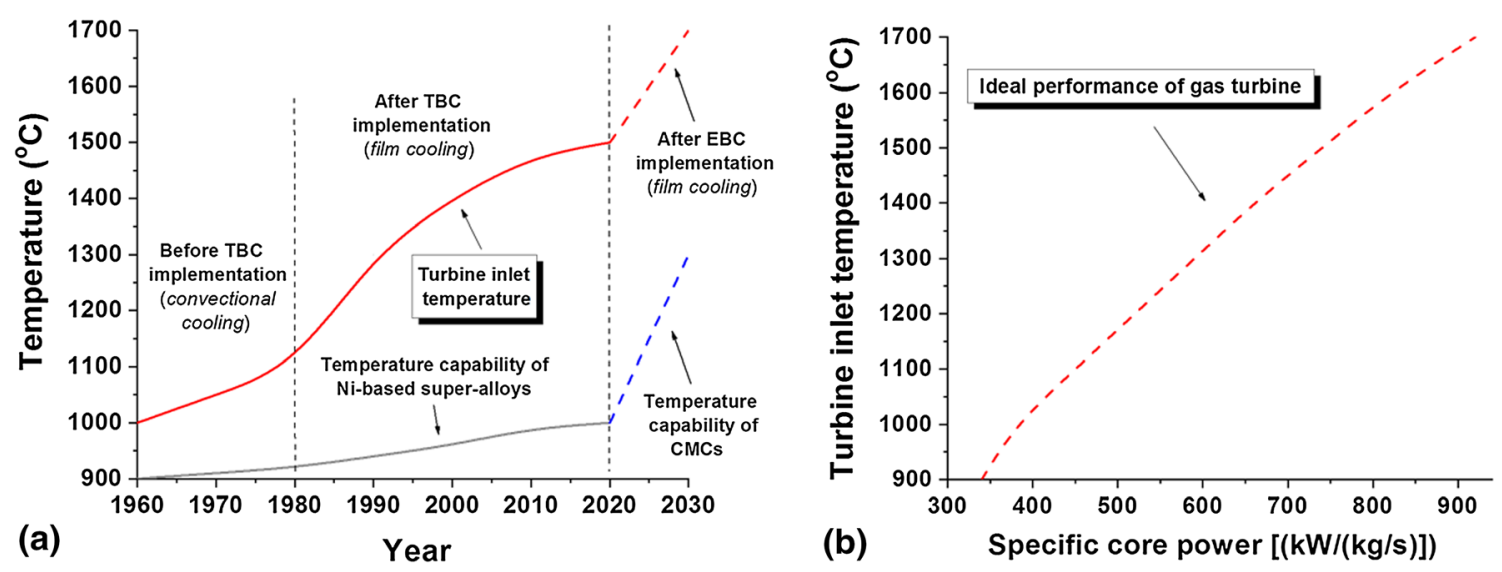

Fig. 2 (a) Evolution of combustion and structural part capability temperatures of gas turbines. Adapted from Padture (Ref 2) and Clarke et al (Ref 11). (b) Combustion temperature as a function of the specific core power of a gas turbine (inverted plot)—adapted from Perepezko (Ref 13)

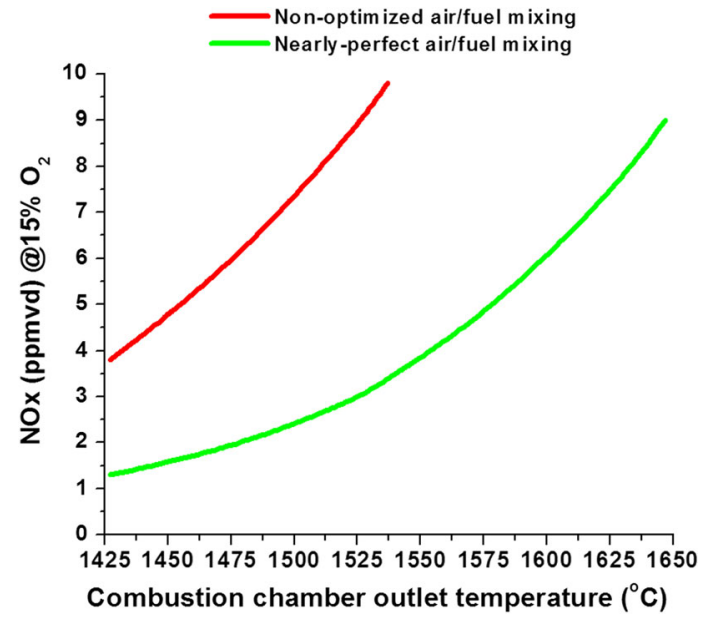

Fig. 3 Effects of the air/fuel mixing optimization on NOx formation in gas turbines engines. Adapted from Leonard and Stegmaier (Ref 17)

of Fig. 2(b) was inverted for "didactic" reasons, in order to match with the temperature range of Fig. 2(a). It shows the ideal relationship between the turbine core power as a function of its TIT; which is the temperature of the combustion gases as they leave the combustion chamber and enter the turbine unit. Between $\sim 900{ }^{\circ} \mathrm{C}$ to $\sim 1700{ }^{\circ} \mathrm{C}$, this relationship is almost linear (fundamentally, the higher the temperature attained in combustion chamber the greater the expansion of the gases and hence the greater the efficiency of the engine). Therefore, TITs higher than the current $\sim 1500{ }^{\circ} \mathrm{C}$ are needed in order to fulfill the insatiable demand for more efficient and powerful turbines. Consequently, EBCs and CMCs will need to be employed in the manufacture of the hot zones of gas turbine engines, if the $\sim 1500{ }^{\circ} \mathrm{C}$ TIT limit is to be effectively surpassed (Fig. 2(a)).

There is a $2^{\text {nd }}$ very important reason to better understand the driving force behind using EBCs/CMCs in gas turbines.
This reason is directly related to environmental regulations, mainly regarding the emissions of nitrogen oxides (NOx) and carbon monoxide $(\mathrm{CO})$ gases.

NOx is a toxic gas not naturally present in the atmosphere. However, it may be naturally created during lighting in thunderstorms. The source of high NOx production on the planet is typically found in all air-hydrocarbon fuel combustion engines, including gas turbines. The high temperatures produced during the combustion create the conditions for $\mathrm{N}_{2}$ and $\mathrm{O}_{2}$ gases present in the air to react and form NOx. NOx in combination with other pollutants in the atmosphere creates the aggressive oxidizer ozone $\left(\mathrm{O}_{3}\right)$ at ground and near ground levels. In addition, NOx collaborates in the production of acid rain.

$\mathrm{CO}$ is also a toxic gas not naturally present in the atmosphere. $\mathrm{CO}$ is called the "silent killer" because it does not naturally occur in the atmosphere. In addition, $\mathrm{CO}$ binds strongly to the hemoglobin in the blood. When people breathe large amounts of $\mathrm{CO}$, it impedes the oxygen to bind with the hemoglobin and the blood loses its ability to transport oxygen, thereby, causing suffocation and loss of consciousness. CO is also created in air-hydrocarbon fuel combustion engines when there is a fuel rich burn, i.e., it lacks $\mathrm{O}_{2}$ in the air to fully oxidize the carbon atoms of the hydrocarbon fuel into carbon dioxide $\left(\mathrm{CO}_{2}\right)$ gas. Although being an un-desired global warming greenhouse gas, the $\mathrm{CO}_{2}$ is rarely poisonous to human beings in low concentrations. $\mathrm{CO}_{2}$ naturally occurs in nature and it is a by-product of human and animal respiration, as well as, plant life.

As previously stated, NOx is formed by the reaction of the $\mathrm{N}_{2}$ and $\mathrm{O}_{2}$ at high temperatures. Lefebvre and Ballal (Ref 14) showed that in conventional metallic-based combustion chambers of gas turbines, the NOx production will become "excessive" (i.e., higher than 15 ppmv) for combustion temperatures higher than $1600{ }^{\circ} \mathrm{C}$. Therefore, 
reaching combustion temperatures levels $\geq 1500{ }^{\circ} \mathrm{C}$ to improve turbine performance, as highlighted in Fig. 2(b), does not seem to be an acceptable option. An increase in efficiency would translate into an unacceptable increase in toxic gas emission levels. However, it is important to point out that in conventional combustion chambers, of the total air that passes by the turbine core; just $\sim 40 \%$ is used for the combustion itself. The other $\sim 60 \%$ is used for film cooling the TBC-coated inner combustion chamber walls, as well as, the backside impingement cooling of the outer walls according to a technical publication from RollsRoyce (Ref 15). Consequently, most of the air that passes by the turbine core is used for cooling the metallic-based conventional combustion chambers.

Interestingly, Bhatia et al (Ref 16) retrofitted an EBCcoated CMC combustion chamber into an aerospace turbine engine. Due to the CMC capacity to operate at higher temperatures, film cooling of the inner walls of the combustion chamber was eliminated and just a limited cooling on the backside wall was employed. By employing this approach, most of the air was then pre-mixed with the fuel (at combustion chamber's dome) and little air was left for cooling. The results showed a $30 \%$ reduction in NOx emissions at full engine power and a $20 \%$ reduction of the $\mathrm{CO}$ emissions at idle engine power (when compared to those of a metallic combustion chamber baseline). The extra air that is injected into the combustion chamber and mixed with the fuel (i) somewhat disrupts the chemical reactions between $\mathrm{N}_{2}$ and $\mathrm{O}_{2}$ that need to occur to form NOx and (ii) creates an oxidizing atmosphere that lowers the production of $\mathrm{CO}$.

These results are confirmed by Leonard and Stegmaier (Ref 17), who analyzed the NOx emissions produced in combustion chambers of gas turbine engines for different air/fuel mixing conditions (Fig. 3).

It was concluded that if NOx emissions are to be reduced, most of the air must be mixed with fuel prior to the combustion and little air needs to be left for cooling. For example, it was reported that NOx levels for non-optimized air/fuel mixing conditions are $\sim 3$ times higher than those of near-perfect air/fuel mixing at TITs of $\sim 1500{ }^{\circ} \mathrm{C}$; which is the current limit of today's engines (Fig. 2(a)). At a temperature of $1640{ }^{\circ} \mathrm{C}$, the NOx emission levels of near-perfect air/fuel mixing is $\sim 9$ ppmvd, whereas that of a non-optimized mixing is $\sim 10 \mathrm{ppmvd}$ at $1540{ }^{\circ} \mathrm{C}$ (maximum temperature measured). Therefore, even operating at a temperature $100{ }^{\circ} \mathrm{C}$ higher (i.e., $1640{ }^{\circ} \mathrm{C}$ versus $1540{ }^{\circ} \mathrm{C}$ ), a near-perfect air/fuel mixing still produces $\sim 10 \%$ lower NOx emission levels than that of a non-optimized air/fuel mixing (Fig. 3).

Environment regulations, like the European Flightpath 2050 (Ref 18), will require a 90\% reduction in NOx emissions produced by the aviation industry by 2050 . The
United States Environmental Protection Agency (EPA) adopted standards for aircraft turbine engines with thrusts greater than $2700 \mathrm{kgf}(6000 \mathrm{lbf})$ in 2012. It requires that all engines certified after January, 01, 2014 must exhibit a $15 \%$ reduction in NOx emissions levels when compared to the previous generation (Ref 19). As the latest generation of the Boeing 737 MAX (2017) has CFM International LEAP-1B engines having $12,700 \mathrm{kgf}(28,000 \mathrm{lbf})$ of thrust each (Ref 20), one can imagine that this standard covers the majority of commercial passenger and cargo aircraft flying in the world.

Consequently, EBCs and CMCs are of paramount importance for manufacturing the next generation of highly efficient and environmentally friendly aerospace and energy generation gas turbines. In the next sections of this manuscript, the EBC/CMC materials, properties and processing will be discussed in more details, as well as, advanced EBC/CMC testing.

\section{EBC Requirements}

EBC degradation can be categorized into two groups: environmental/chemical and thermal/thermo-mechanical. Environmental/chemical degradation includes the water vapor-induced recession, the water vapor-induced oxidation, and the degradation by Calcium-Magnesium-Aluminum-Silicate (CMAS) deposits. Thermal and thermomechanical degradation includes the degradation due to thermal and thermo-mechanical stresses, particle erosion, and foreign object damage (FOD). Figure 4 schematically shows various EBC degradation and failure modes. In services various degradation modes interact with each other, leading to complex EBC failure modes (Ref 21).

The goal of EBCs is to protect EBC/CMC systems from various degradation modes and thereby maximize the life of EBC/CMC systems. EBC requirements to achieve this goal include: (i) environmental stability in $\mathrm{H}_{2} \mathrm{O}$ (ii) and CMAS; (iii) chemical compatibility with CMC; (iv) adherence to CMC; and (v) low residual stresses (Ref 22). Low residual stresses require a good thermal expansion match with CMC, phase stability, low modulus and sinter resistance.

EBC Stresses EBCs fail, in most cases, due to stresses regardless of whether the degradation mode is environmental, chemical, thermal or thermo-mechanical. The EBC stress $\left(\sigma_{\mathrm{EBC}}\right)$ on $\mathrm{CMC}$ substrates may be divided into three components:

$\sigma_{E B C}=\sigma_{t}+\sigma_{a}+\sigma_{g}$

where $\sigma_{\mathrm{t}}$ is the thermal mismatch stress, $\sigma_{\mathrm{a}}$ is the aging stress, and $\sigma_{\mathrm{g}}$ is the growth stress (Ref 23).

The thermal mismatch stress is given by 
Fig. 4 Schematics illustrating key EBC failure modes. Source: Ref. 21

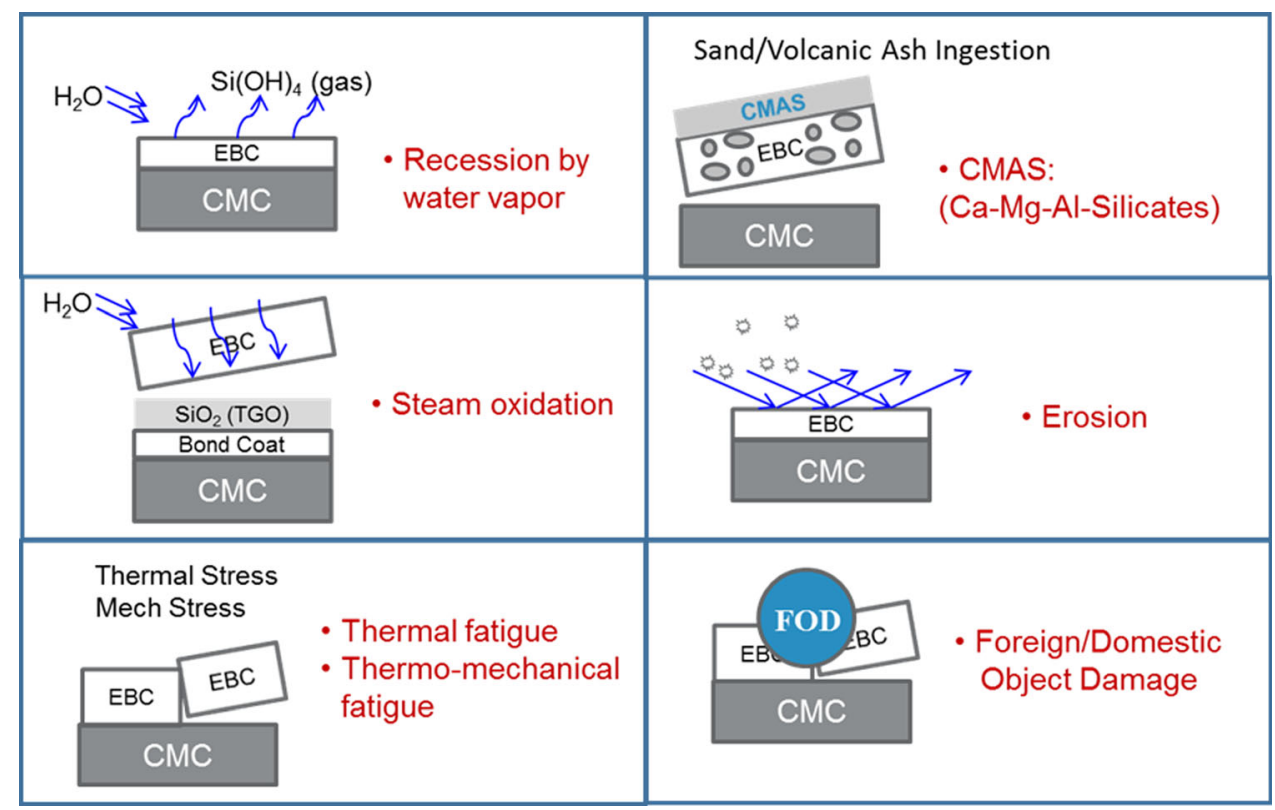

$\sigma_{t}=\frac{\left(\alpha_{\mathrm{EBC}}-\alpha_{\mathrm{CMC}}\right) E_{\mathrm{EBC}} \Delta T}{\left(1-v_{\mathrm{EBC}}\right)}$

where $\alpha_{\mathrm{EBC}}$ and $\alpha_{\mathrm{CMC}}$ are the coefficients of thermal expansion (CTE) for $\mathrm{EBC}$ and the CMC substrate, respectively, $E_{\mathrm{EBC}}$ is the Young's modulus of EBC, and $v_{\mathrm{c}}$ is the Poisson's ratio of EBC ( Ref 23$)$. The aging stress is a stress due to the changes in physical, mechanical and chemical properties of EBC that are induced by thermal exposures. Factors causing these changes include oxidation, chemical reactions, phase transformations, and sintering. The growth stress is a stress that develops during the EBC deposition. There are other stresses not addressed in Eq. 1 such as the thermal shock stress induced by temperature gradient. A brief description of each EBC requirement with regard to $\mathrm{SiC} / \mathrm{SiC} \mathrm{CMCs}$ and its implications on EBC failure are described. The same principle applies to oxide/oxide CMCs.

Water Vapor Stability The dependence of EBC volatility on various parameters can be expressed by the silica volatility model developed by Opila et al. (Ref 24):

$\mathrm{J}\left(\mathrm{Si}(\mathrm{OH})_{4}\right) \mu \mathrm{a}\left(\mathrm{SiO}_{2}\right) v^{1 / 2} \mathrm{P}\left(\mathrm{H}_{2} \mathrm{O}\right)^{2}\left(\mathrm{P}_{\text {total }}\right)^{-1 / 2}$

where $\mathrm{J}\left(\mathrm{Si}(\mathrm{OH})_{4}\right)$ is the $\mathrm{SiO}_{2}$ volatility, $\mathrm{a}\left(\mathrm{SiO}_{2}\right)$ is the silica activity of EBC, $v$ is the gas velocity, $\mathrm{P}\left(\mathrm{H}_{2} \mathrm{O}\right)$ is the water vapor pressure, and $P_{\text {total }}$ is the total pressure. Materials with a lower silica activity, therefore, are preferable for water vapor stability. The volatility of silica, mullite, and BSAS $\left((1-x) \mathrm{BaO}-x \mathrm{SrO}-\mathrm{Al}_{2} \mathrm{O}_{3}-2 \mathrm{SiO}_{2} ; 0 \leq x \leq 1\right)$ was calculated using the silica volatility model (Eq. 3), thermodynamics and kinetics database, and the first principle calculations (Ref 25). BSAS was most stable in water vapor, followed by mullite and SiC. The volatility of BSAS and various rare earth silicates were determined using the steam TGA (thermogravimetric analysis) (Ref 26). Rare earth disilicates, such as $\mathrm{Yb}_{2} \mathrm{Si}_{2} \mathrm{O}_{7}$ and $\mathrm{Y}_{2} \mathrm{Si}_{2} \mathrm{O}_{7}$, exhibited volatilities similar to that of $\mathrm{BSAS}$, while rare earth monosilicates, such as $\mathrm{Yb}_{2} \mathrm{SiO}_{5}$ and $\mathrm{Y}_{2} \mathrm{SiO}_{5}$, showed much lower volatilities. The low volatilities of rare earth monosilicates were attributed to their lower silica activities, by about two orders of magnitude, compared to the silica activities of rare earth disilicates (Ref 27, 28). Combining the data from the Ref. 25 and 26, the volatility ranking among silicates is mullite $>$ BSAS, rare earth disilicates $>$ rare earth monosilicates. Rare earth silicates vaporize in water vapor according to the following reactions (Ref 25).

$\mathrm{RE}_{2} \mathrm{Si}_{2} \mathrm{O}_{7}+2 \mathrm{H}_{2} \mathrm{O}(\mathrm{g})=\mathrm{RE}_{2} \mathrm{SiO}_{5}+\mathrm{Si}(\mathrm{OH})_{4}(\mathrm{~g})$

$\mathrm{RE}_{2} \mathrm{SiO}_{5}+2 \mathrm{H}_{2} \mathrm{O}(\mathrm{g})=\mathrm{RE}_{2} \mathrm{O}_{3}+\mathrm{Si}(\mathrm{OH})_{4}(\mathrm{~g})$

Using $\mathrm{Yb}$ as an example, $\mathrm{Yb}_{2} \mathrm{O}_{3}$ has the highest $\mathrm{CTE}$ $\left(8.5 \times 10^{-6} /{ }^{\circ} \mathrm{C}\right)$ followed by $\mathrm{Yb}_{2} \mathrm{SiO}_{5}\left(7-8 \times 10^{-6} /{ }^{\circ} \mathrm{C}\right)$ and $\mathrm{Yb}_{2} \mathrm{Si}_{2} \mathrm{O}_{7}\left(\sim 4.6 \times 10^{-6} /{ }^{\circ} \mathrm{C}\right)($ Ref 25$)$. Recession studies on $\mathrm{RE}$ disilicates in high-velocity, high-steam rig tests confirmed the formation of RE monosilicate surface layer according to Eq. 4 ( $\operatorname{Ref} 29,30)$. The RE monosilicate surface layer, due to its high CTE, increases the EBC residual stress according to Eq. 2.

Oxidation Resistance Water vapor is the primary oxidant for silicon and $\mathrm{SiC}$ in combustion environments because the permeability of $\mathrm{H}_{2} \mathrm{O}$ in $\mathrm{SiO}_{2}$ is about 10-times higher than that of oxygen $(\operatorname{Ref} 31,32)$. Thermally grown 
oxide (TGO) causes stresses due to the 2.2-fold volume expansion during the oxidation of silicon to $\mathrm{SiO}_{2} \mathrm{TGO}$, the CTE mismatch between the cristobalite $\mathrm{SiO}_{2}$ TGO $\left(10.3 \times 10^{-6 /{ }^{\circ} \mathrm{C}}\right)$ and the $\mathrm{CMC}\left(\sim 4-5 \times 10^{-6} /{ }^{\circ} \mathrm{C}\right)$, and the $\beta$ to $\alpha$ cristobalite $\mathrm{SiO}_{2}$ TGO phase transformation at about $200{ }^{\circ} \mathrm{C}$, which is accompanied by about 5 percent volume reduction (Ref 21,33). Identified in laboratory tests and confirmed in rig and engine tests, the spallation due to the TGO growth is one of the most frequently observed EBC failure modes (Ref 34). It is believed that the strain energy associated with the residual stress caused by the TGO are primarily responsible for the oxidation-induced EBC failure.

CMAS Resistance EBC degradation by CMAS is a glass ceiling to the upper use temperature of current EBCs. CMAS deposits form when air-breathing turbine engines ingest particulates such as sand, volcanic ash, and other siliceous debris. Ingested particulates can cause several issues. At temperatures above about $1230{ }^{\circ} \mathrm{C}\left(2246^{\circ} \mathrm{F}\right)$, CMAS melts and adheres to hot section components, resulting in undesirable chemical reactions with EBCs which can cause an aging stress. Additionally, molten CMAS can infiltrate porous EBCs, which increases the modulus and therefore increases the EBC stress. Current silicate-based EBCs do not afford an adequate protection against the CMAS degradation (Ref 35-39).

Chemical Compatibility Most of the current EBC candidates, i.e., oxides and silicates, have a high tendency to react with each other at high temperatures. In multilayer, EBCs chemical reactions between adjacent layers can alter the EBC physical and mechanical properties that causes increased residual stresses. The eutectic formation at the BSAS/SiO 2 interface $\left(\mathrm{mp} \sim 1300{ }^{\circ} \mathrm{C}\right)$ and the $\mathrm{Y}_{2} \mathrm{Si}_{2} \mathrm{O}_{7} /$ mullite interface $\left(\mathrm{mp} \sim 1400{ }^{\circ} \mathrm{C}\right)$, and the RE disilicate formation at the $\mathrm{SiO}_{2} / \mathrm{RE}$ monosilicate interface are the examples of interfaces that must be avoided to prevent chemical reactions ( $\operatorname{Ref} 7,25,26)$.

Adherence A weak EBC/CMC interfacial adherence leads to a fast TGO growth, and therefore, a short $\mathrm{EBC}$ life. There are two types of EBC/CMC interfacial bonding: mechanical and chemical. The mechanical bonding can be improved by roughening the CMC surface via grit blasting, surface patterning, or chemical etching. The chemical bonding can be improved via deposition process optimization or a judicious selection of coating chemistry. Processes involving high temperatures and/or chemical reactions, such as the chemical vapor deposition and the electron beam-physical vapor deposition (EB-PVD), are known to provide a good chemical bonding. Selecting a coating chemistry that has a limited inter-diffusion or chemical reaction with CMC can also provide a good chemical bonding. Refractory oxide or silicate EBCs in general do not bond very well onto $\mathrm{CMC}$, and therefore, a bond coat is needed to improve the bonding. Currently silicon is the most effective bond coat due to the excellent adherence with $\mathrm{EBC}$ and $\mathrm{CMC}$, the close thermal expansion match with CMC, and the excellent oxidation resistance (Ref 25). Silicon has the best oxidation resistance among all metals and metal alloys in the CMC application temperature range $\left(>1000{ }^{\circ} \mathrm{C}\right)(\operatorname{Ref} 25)$.

Thermal Expansion Due to the relatively low CTE of CMC $\left(4-5.3 \times 10^{-6} /{ }^{\circ} \mathrm{C}\right)$, viable candidate materials from the CTE standpoint is quite limited. The traditional high temperature refractory oxides, such as alumina, zirconia, and hafnia, have significantly higher $(\sim 2 \mathrm{x})$ CTEs than $\mathrm{SiC}$, making them poor EBC candidates. Refractory silicates, such as mullite, BSAS, and rare earth disilicates, on the other hand have a very close CTE match with $\mathrm{SiC}$, and therefore, have attracted most interests as EBC candidates (Ref 25, 40).

Phase Stability Phase transformations are generally accompanied by a volume change, which in turn leads to aging stresses. The plasma-sprayed mullite coating is a good example of an EBC that undergoes a detrimental phase transformation. A significant amount of amorphous phase forms in conventional plasma spraying of mullite, which transforms to the crystalline mullite at $\sim 1000{ }^{\circ} \mathrm{C}$. This transformation is accompanied by a volumetric shrinkage, causing significant cracking and a short EBC life (Ref 41). BSAS and rare earth disilicates, such as $\mathrm{Y}_{2} \mathrm{Si}_{2} \mathrm{O}_{7}$ and $\mathrm{Yb}_{2} \mathrm{Si}_{2} \mathrm{O}_{7}$, form a glass as well as metastable phases in conventional plasma spraying (Ref 21, 23). The detrimental effect of $\mathrm{Y}_{2} \mathrm{Si}_{2} \mathrm{O}_{7}$ phase transformation in a rig test is reported in Ref. 42. Various approaches to mitigate the formation of glass and metastable phases through processing is described in the section on EBC Processing \& Manufacturing via Air Plasma Spray.

Low Modulus A low modulus reduces EBC stresses according to Eq. 2. The EBC modulus can be reduced by introducing pores. Columnar pores can be introduced using EB-PVD, PS-PVD (plasma spray physical vapor deposition) or SPS (suspension plasma spraying) processes. Random pores can be introduced using plasma spraying by either adjusting the process parameters or by spraying with a fugitive material which is burned-off during the postprocess heat treatment. Columnar structures via EB-PVD are widely used in fabricating thermal barrier coatings for airfoils, while plasma spraying with a fugitive material is widely used in fabricating porous abradables. Pores, however, can be detrimental to the oxidation resistance if they are interconnected and thereby provide easy paths for water vapor diffusion. A delicate balance between the stress management and the oxidation mitigation is needed for an optimal EBC performance. 


\section{EBC Materials}

The EBC material selection with regard to $\mathrm{SiC} / \mathrm{SiC}$ CMCs is described in this section, however, the sample principle applies to oxide/oxide CMCs. No single material satisfies all the $\mathrm{EBC}$ requirements due to the very demanding nature of the requirements described in the previous section. Current EBCs, therefore, evolved into multilayer coatings (Ref 25, 40). An EBC, at the minimum, comprises a bond coat and a top coat where the bond coat facilitates the oxidation resistance and the adherence, while the top coat facilitates the protection from the recession by water vapor. Additional layers may be incorporated between the bond coat and the top coat and/or above the top coat to facilitate various functionalities, such as the chemical compatibility, the CTE transition, the compliance, the water vapor stability, the CMAS resistance, the high temperature capability, and the low thermal conductivity. Current EBCs are based on the silicon bond coat and the ceramic layer(s) of mullite, BSAS, and/or rare earth silicates (Ref 25, 40). The silicon bond coat provides excellent adherence to the CMC and oxidation resistance. Mullite is a good chemical barrier between the $\mathrm{SiO}_{2} \mathrm{TGO}$ and the top coat in the Si/mullite/BSAS EBC (Ref 7) and the Si/mullite/RE monosilicate EBC (Ref 26). Rare earth disilicates are compatible with the $\mathrm{SiO}_{2} \mathrm{TGO}$ and therefore the $\mathrm{Si} / \mathrm{rare}$ earth disilicate two-layer EBC works quite well.

BSAS and RE disilicates provide a decent protection against the recession by water vapor, however, neither is suitable for a long-term protection $(>10,000 \mathrm{hr})$ in advanced gas turbines that run at high temperatures and pressures which accelerate the recession by water vapor. An overlay coating with a higher resistance to water vapor is therefore required. RE monosilicates have a far superior recession resistance to RE disilicates because of their very low silica activities (Ref 26-28). RE monosilicates, however, have higher CTEs than CMCs, increasing the residual stress. Curvatures on gas turbine components such as blades and vanes also have implications on coating stresses. An analytical model of TBC residual stresses on a cylindrical substrate showed that the tensile radial stress increases with decreasing the radius of curvature (Ref 43). For Example, the maximum tensile radial stress increases by about $65 \%$ when the substrate curvature increases by a factor of 4 (Ref 43). This implies curvatures on gas turbine components further exacerbate the residual stress issue associated with a high CTE overlay coating.

Gatzen et al. (Ref 44) compiled various oxides and silicates according to their recession rates and CTEs by using the data from the Refs. 29, 45, 46 (Fig. 5). Note that the oxides and silicates with the highest resistance to water vapor have CTEs higher than $\mathrm{SiC} / \mathrm{SiC}$ CMCs. Thermal

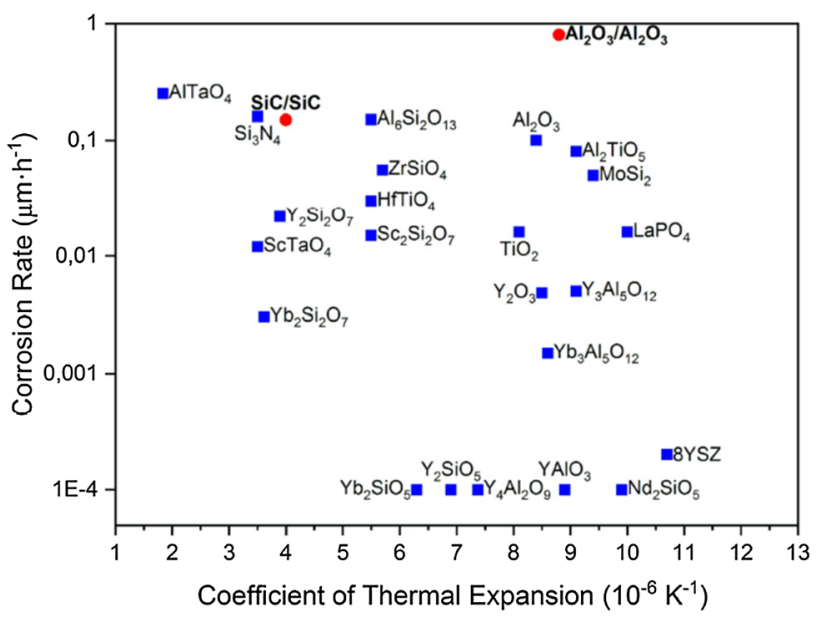

Fig. 5 Recession rates and coefficient of thermal expansion various oxides and CMCs. Source: Ref. 44

stresses, therefore, must be mitigated before these materials can be used as a recession barrier. Reducing the modulus is one way to mitigate the CTE mismatch stress. Strategies to reduce the modulus were discussed in the previous section. A CTE transition layer with an intermediate CTE in conjunction with a compositional grading is another viable option to mitigate the CTE mismatch stress between two EBC layers.

The CMAS-resistant EBC research focuses on a multilayer coating architecture, where the top layer arrests the CMAS penetration at or near the surface, while the underlying layers provide the protection from the oxidation (Ref 34). At present, gadolinium zirconate $\left(\mathrm{Gd}_{2} \mathrm{Zr}_{2} \mathrm{O}_{7}\right)$, which was invented as a TBC, shows the best promise to arrest the CMAS infiltration. Understanding the effect of CMAS composition as well as trace oxides in volcanic ash or regional sand on the crystallization, the viscosity, the thermal and mechanical properties, and the chemical reactivity with EBCs is an important step toward developing the strategies to mitigate the CMAS degradation. Advanced EBC technologies via new compositions, architectures, and modeling are a promising route to develop the tools needed to protect the next-generation CMC components from CMAS. Similar to the recessionresistant overlay coating mitigating the CTE mismatch and the chemical compatibility will be critical.

A logical approach to improve the EBC oxidation life is to reduce the TGO growth rates. The TGO growth rates can be reduced by reducing the permeability of oxidants through the EBC and/or the TGO. In TBC-coated superalloys, the TBC life was significantly improved by reducing the $\mathrm{Al}_{2} \mathrm{O}_{3}$ TGO growth rates on the bond coat by adding reactive elements, such as $\mathrm{Y}, \mathrm{Zr}$ and $\mathrm{Hf}$, in the $\mathrm{Al}_{2} \mathrm{O}_{3}$-forming bond coat. These additives significantly reduced the TGO growth rates by reducing the diffusivity 
of oxygen through the TGO. A recent breakthrough in improving the EBC oxidation life through the reduction of the $\mathrm{SiO}_{2}$ TGO growth rates is reported by Lee (Ref 21). Adding $\mathrm{Al}_{2} \mathrm{O}_{3}$ or $\mathrm{Al}_{2} \mathrm{O}_{3}$-containing oxide compounds, such as mullite and $\mathrm{YAG}\left(\mathrm{Y}_{3} \mathrm{Al}_{5} \mathrm{O}_{12}\right)$, in the top coat of the silicon/ $/ \mathrm{Yb}_{2} \mathrm{Si}_{2} \mathrm{O}_{7} \mathrm{EBC}$ reduced the $\mathrm{SiO}_{2}$ TGO thickness by up to about 80 percent compared to the baseline silicon/ $\mathrm{Yb}_{2} \mathrm{Si}_{2} \mathrm{O}_{7} \mathrm{EBC}$ after 1000 one-hour cycles at $1316{ }^{\circ} \mathrm{C}$ in a steam environment. Figure 6 compares the EBC crosssection of the $\mathrm{Si} / \mathrm{Yb}_{2} \mathrm{Si}_{2} \mathrm{O}_{7}$ and the $\mathrm{Si} / \mathrm{Yb}_{2} \mathrm{Si}_{2} \mathrm{O}_{7}+4.66$ wt.\% YAG + 1.39 wt.\% mullite EBCs after 1000 1-hour cycles at $T=1316{ }^{\circ} \mathrm{C}, \mathrm{P}\left(\mathrm{H}_{2} \mathrm{O}\right)=0.9 \mathrm{~atm}, P_{\text {total }}=1 \mathrm{~atm}$, and $v=10 \mathrm{~cm} / \mathrm{s}$. The reduced TGO growth rates theoretically translate to an approximately 20-fold improvement in the EBC life. It was proposed that the TGO became less permeable to $\mathrm{H}_{2} \mathrm{O}$ because the $\mathrm{Al}_{2} \mathrm{O}_{3}$ from the oxide additives modified the $\mathrm{SiO}_{2}$ network structure (Ref 21).

Thermal and aging stresses can be minimized by carefully selecting the coating materials based on their chemical, mechanical, and physical properties. Thermal stresses can be minimized by selecting the coating materials having CTEs that closely match the CTE of the substrate and low Young's moduli. Aging stresses can be minimized by selecting the coating materials that maintain stable phases during thermal excursions, possess high sintering temperatures, possess low $\mathrm{H}_{2} \mathrm{O}$ permeabilities, and are chemically compatible with the substrate as well as with the other EBC layers.

The temperature capability goal for the next-generation $\mathrm{CMCs}$ is $1482{ }^{\circ} \mathrm{C}\left(2700^{\circ} \mathrm{F}\right)$. This requires a new class of
EBC bond coat materials with a $1482{ }^{\circ} \mathrm{C}$ temperature capability. The new bond coat materials will likely be based on ceramics because no metallic materials are viable at $1482{ }^{\circ} \mathrm{C}$ in oxidizing environments. NASA Glenn Research Center recently developed an EBC with a $\mathrm{Yb}_{2}$ $\mathrm{Si}_{2} \mathrm{O}_{7^{-}}$and mullite-based bond coat using a slurry process (Ref 34). Slurry EBC-coated CMC coupons demonstrated a 500 one-hour cycle durability at $1427^{\circ} \mathrm{C}\left(2600^{\circ} \mathrm{F}\right)$ in steam oxidation tests, and a slurry EBC-coated CMC airfoil $\left(3^{\prime \prime} \times 3^{\prime \prime}\right)$ demonstrated a $15 \mathrm{~h}-150$ cycle durability at 1371-1482 ${ }^{\circ} \mathrm{C}$ in a Pratt \& Whitney combustion rig test $\left(\mathrm{P}\left(\mathrm{H}_{2} \mathrm{O}\right) \sim 0.82 \mathrm{~atm}, P_{\text {total }} \sim 8.2 \mathrm{~atm}, \quad v \sim 116 \mathrm{~m} / \mathrm{s}\right.$, delta $\mathrm{T}$ across $\left.\mathrm{EBC}+\mathrm{CMC}=100-150{ }^{\circ} \mathrm{C}\right)$. Two $\mathrm{CMC}$ airfoil spacers $\left(3^{\prime \prime} \times 1^{\prime \prime}\right)$ coated with the same EBC were placed between the $3^{\prime \prime} \times 3^{\prime \prime}$ CMC airfoil and the inner wall of the test section to seal the gaps. After a $50 \mathrm{~h}-500$ cycle exposure at $1371{ }^{\circ} \mathrm{C}-1482{ }^{\circ} \mathrm{C}$, the $\mathrm{CMC}$ spacers were intact, while the $\mathrm{CMC}$ airfoil showed a limited spallation along the leading edge, with the spallation occurring mostly at the bond coat-top coat interface. These results demonstrated the potential for an oxide-based bond coat to meet the higher temperature requirements of the nextgeneration EBCs.

The surface temperature goal of the next-generation EBCs is $1650{ }^{\circ} \mathrm{C}\left(3000{ }^{\circ} \mathrm{F}\right)$. The water vapor recession and the CMAS degradation are the most critical challenges to achieve this goal. Recession- and CMAS-resistant compositions capable of $1650{ }^{\circ} \mathrm{C}$ must be incorporated in the EBC top coat, which will require a delicate balance among

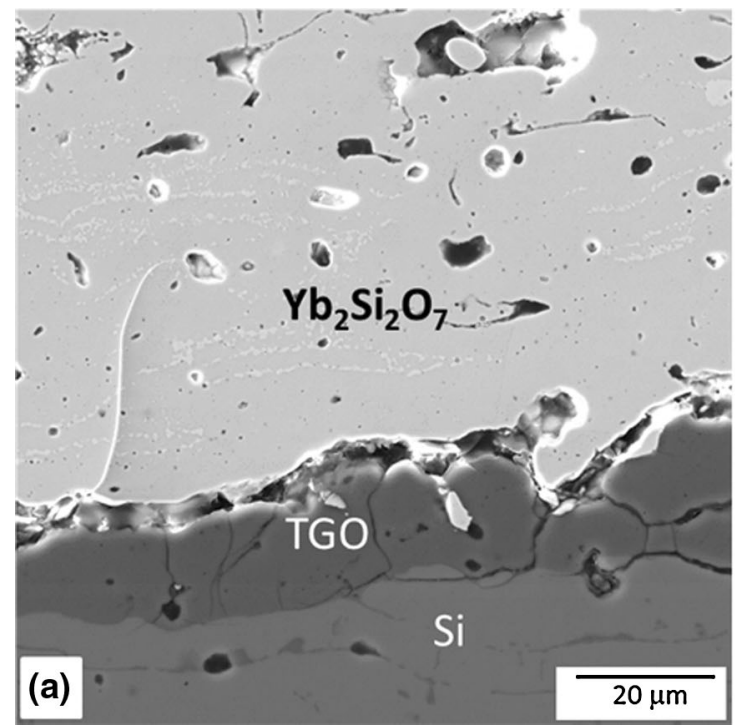

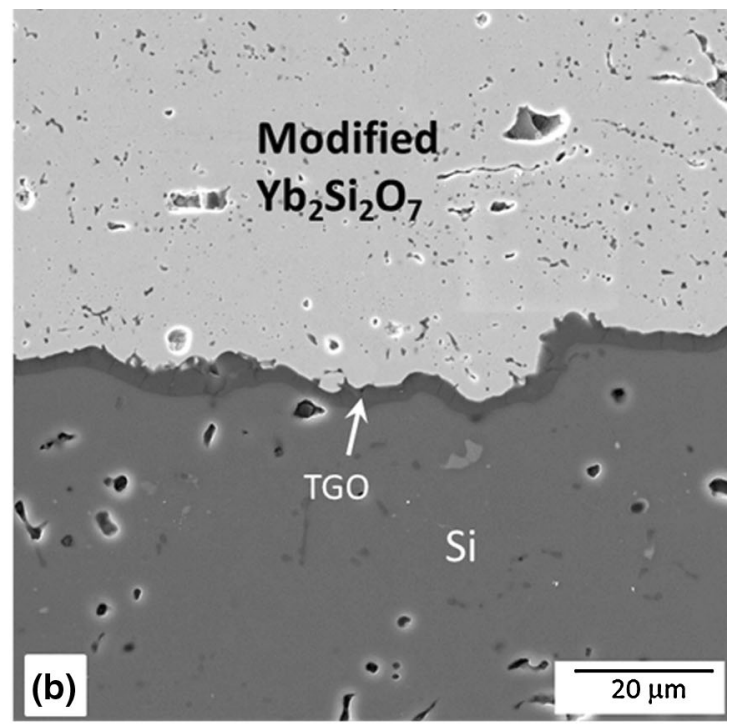

Fig. 6 Cross section of (a) silicon/Yb2Si2O7 and (b) silicon/Yb2Si2O7 + 4.66 wt.\% YAG + 1.39 wt.\% mullite EBCs on CMC after 1000 1-hour cycles at $T=1316^{\circ} \mathrm{C}, \mathrm{P}(\mathrm{H} 2 \mathrm{O})=0.9 \mathrm{~atm}$, Ptotal $=1 \mathrm{~atm}$, and $\mathrm{v}=10 \mathrm{~cm} / \mathrm{s}$. Source: Ref. 21 
the various durability requirements, including the recession, the CMAS durability and the thermal stress.

\section{EBC Processing and Manufacturing via Air Plasma Spray (APS)}

\section{Initial Success of the APS Technique}

Thermal spraying has been the most widely used processing technique to deposit EBCs, more specifically, air plasma spray (APS). One of the main reasons for this is the successful application of TBCs in gas turbines via APS since the 1980s. The industry knows that this is a reliable process, which is widely available in different parts of the world. Sound industrial supply chains involving equipment/feedstock suppliers and service centers are already established and a solid scientific community is already implemented.

\section{Processing and Manufacturing of EBCs Sprayed on $\mathrm{SiC} / \mathrm{SiC}$ CMCs via APS}

Although thermal spraying has been the preferred manufacturing technique to deposit $\mathrm{EBCs}$, it does have a major challenge during spraying on $\mathrm{SiC} / \mathrm{SiC} \mathrm{CMC}$ substrates. EBC materials for $\mathrm{SiC} / \mathrm{SiC} \mathrm{CMC}$ substrates like mullite, BSAS and RE-silicates typically exhibit their stable (i.e., desirable) phases in narrow ranges (areas) of their phase diagrams. When thermally sprayed, the powder particles of these feedstock materials get fully or partially melted during their dwell time in the thermal spray jet. Upon reaching the substrate surface, these thermally sprayed particles are subjected to high solidification rates. In addition, these silicates have a tendency to form glassy phases. These two events combined typically lead to the formation of fully or partially amorphous, as well as, metastable phases. These amorphous and metastable phases (coatings) are not desirable because they crystallize when exposed to high temperatures (in which they are supposed to operate). The crystallization process induces phase transformations that result in volume changes and the associated stresses at high temperatures. Moreover, amorphous and metastable phases often display CTE values significantly different from that of their stable phases and CMC substrates. The mismatched CTE values are another source of stress to the coating/substrate system. As ceramic materials exhibit low plasticity, they are not able to accommodate these stress levels, thereby leading to crack networking formation. As consequences of these crack networking formations, the EBCs lose their gas-tight characteristics and they can even spall-off the substrate, as reported by Lee et al. (Ref 41$)$.
Based on this crystallization challenge, different researchers have suggested distinct approaches to overcome it. Basically, there is the need to crystallize these EBCs before putting them into engines, where they will need to operate at the temperature levels higher than those of current APS YSZ TBCs; which is about $1300{ }^{\circ} \mathrm{C}$ at maximum turbine power. It needs to be pointed out that mullite, BSAS and RE silicates will crystallize before $1300{ }^{\circ} \mathrm{C}$. At this moment there are few major techniques employed to overcome this challenge. They are described below.

\section{Assisted Heating Technique}

The assisted heating technique has been firstly proposed by Lee et al. (Ref 41). Chiefly, it teaches to place the ceramic substrate inside a furnace at high temperature level (i.e., the source for assisted heating), generally at or above the stable phase crystallization temperature of the material to be sprayed. Therefore, during spraying, when the sprayed particles arrive at the substrate surface, their cooling rates are reduced. These reduced cooling rates and the high temperature levels of the substrate (at or above the stable phase crystallization temperature) promote the deposition of highly crystalline as-sprayed coatings.

This assisted heating technique has also been employed by Richards et al. (Ref 47) to spray EBC materials, including silicon $(\mathrm{Si})$, mullite $\left(\mathrm{Al}_{6} \mathrm{Si}_{2} \mathrm{O}_{13}\right)$ and ytterbium disilicate $\left(\mathrm{Yb}_{2} \mathrm{Si}_{2} \mathrm{O}_{7}-\mathrm{YbDS}\right)$. The $\mathrm{SiC}$ substrate was placed in a box furnace at a temperature of $1200{ }^{\circ} \mathrm{C}$ during the APS deposition. Specifically for the $\mathrm{Yb}_{2} \mathrm{Si}_{2} \mathrm{O}_{7}$ feedstock powder sprayed, x-ray diffraction (XRD) results showed that highly crystalline as-sprayed RE silicates were formed and the presence of an amorphous phase was negligible. Although the "preferable" $\mathrm{Yb}_{2} \mathrm{Si}_{2} \mathrm{O}_{7}$ phase was detected, the presence of the two $\mathrm{Yb}_{2} \mathrm{SiO}_{5}$ (ytterbium monosilicate-YbMS) phases were also observed in the assprayed $\mathrm{EBC}$, including a metastable one. The presence of the $\mathrm{Yb}_{2} \mathrm{SiO}_{5}$ was probably associated with the loss (i.e., volatilization) of $\mathrm{SiO}_{2}$ during the spraying of the $\mathrm{Yb}_{2} \mathrm{Si}_{2} \mathrm{O}_{7}$ powder. However, as reported by Garcia et al. (Ref 48), differential thermal analysis (DTA) of RE silicate APS coatings showed that the last exothermic peak for crystallization of the metastable YbMS to the stable YbMS occurred at $1221{ }^{\circ} \mathrm{C}$. Consequently, perhaps the $1200{ }^{\circ} \mathrm{C}$ box furnace temperature employed by Richards et al. (Ref 47) was "borderline". Posteriorly after spraying, Richards et al. (Ref 47) performed a regular heat treatment at $1300{ }^{\circ} \mathrm{C}$ for $10 \mathrm{~h}$ in air on the samples. The presence of the $\mathrm{Yb}_{2} \mathrm{Si}_{2} \mathrm{O}_{7}$ and $\mathrm{Yb}_{2} \mathrm{SiO}_{5}$ phases were still detected, whereas the metastable monosilicate transformed into its stable one. For this reason, even with the assisted heating technique, a regular heat treatment may be necessary in order to provide 
a "sturdy" stabilization of EBCs before they are put into service.

\section{Traditional APS Processing and Conventional Post-spray Heat Treatment Technique}

Bakan et al. (Ref 49) deposited a YbDS-based powder on $\mathrm{Si}$ bond-coated $\mathrm{SiC}$ substrates without using any assisted heating. As the substrate temperature levels were below those of the crystallization temperatures for Yb-silicates, the as-sprayed coating was fully amorphous. After spraying, a conventional post-spray heat treatment in air was performed; which consisted of a temperature of $1200{ }^{\circ} \mathrm{C}$ for $25 \mathrm{~h}$. The Yb-silicate EBC became highly crystalline (YbDS and YbMS mix) after the heat treatment. Apparently, the stresses generated by the phase transformations and CTE mismatches did not cause the spallation of the coating.

\section{Controlled APS Processing and Bespoke Post-spray Heat Treatment Technique}

The controlled processing and bespoke post-spray heat treatment technique has been firstly proposed by Garcia et al. (Ref 48). Chiefly, the overall processing is divided into two major parts. Firstly, it teaches to adjust the plasma power and chemistry (i.e., combination of the plasma gases and their respective flows) to minimize the $\mathrm{SiO}_{2}$ volatilization when spraying a $\mathrm{Yb}_{2} \mathrm{Si}_{2} \mathrm{O}_{7}$ feedstock; thereby maximizing the presence of the $\mathrm{Yb}_{2} \mathrm{Si}_{2} \mathrm{O}_{7}$ phase, either crystalline or amorphous in the as-sprayed coating. The coatings are deposited via APS in the exact same traditional method as YSZ TBCs are sprayed today, i.e., there is no need to put the substrate inside a furnace at high temperatures and the sample temperatures during spraying are at the typical ones found for regular APS processing. Secondly, it teaches to perform a bespoke heat treatment technique (in air) on the as-sprayed EBCs to slowly crystalize them before they are put into service. The bespoke heat treatment is designed based on the individual (i) CTE values and (ii) crystallization temperatures of the different phases of the EBCs, from as-sprayed until full crystallization. It consists of 5 heating ramps and 5 plateau temperatures, each one higher than the other, until reaching a maximum temperature of $1300{ }^{\circ} \mathrm{C}$. The total process lasts for over $48 \mathrm{~h}$ (including the cooling rate).

The key reason why this heat treatment is carefully designed is based on what was discussed in previously. Briefly, during the heating phase the stresses generated by the phase transformations and CTE mismatches need to be carefully managed to avoid the extensive cracking and spallation of the EBC.

\section{APS Torch Input Heating to Crystallization}

Bakan et al. (Ref 50) employed the heat generated by an APS torch to the substrate to allow the crystallization of Yb-silicate based coatings, while spraying. Highly crystalline as-sprayed coatings were obtained as the result of (i) high plasma current (i.e., power), (ii) short spray distances $(9 \mathrm{~cm})$ and (iii) a small coupon sample. The temperature of the samples during spraying could not be measured by using a pyrometer or thermocouple because of the rotation of the substrate coupon during spraying, the short spray distance $(9 \mathrm{~cm})$ and the small size of the sample. However, the crystallinity levels observed via XRD indirectly showed that during spraying, the crystallization temperatures of the $\mathrm{Yb}$-silicate phases were achieved.

\section{Processing and Manufacturing of EBCs Sprayed on Oxide-Oxide CMCs}

As discussed in Section 3, suitable EBC materials must exhibit high water vapor stability and CTE values similar to that of the CMC substrate. Moreover, chemical compatibility with the substrate, CMAS attack resistance and phase stability at high temperatures are also important. Low-thermal conductivity values are also desirable. Finally, high erosion resistance is also a mandatory requirement for any coating operating in the hot section of turbines. Based on these facts, Mechnich and Braue (Ref 10) proposed the use of yttria $\left(\mathrm{Y}_{2} \mathrm{O}_{3}\right)$ as EBCs. Vaßen et al. (Ref 51) also proposed the use of $\mathrm{Y}_{2} \mathrm{O}_{3}$, as well as, gadolinium zirconate $\left(\mathrm{Gd}_{2} \mathrm{Zr}_{2} \mathrm{O}_{7}\right)$ and yttrium-aluminumgarnet $\left(\mathrm{Y}_{3} \mathrm{Al}_{5} \mathrm{O}_{12}\right)$. Gatzen et al. (Ref 44) proposed yttriumaluminum perovskite $\left(\mathrm{YAlO}_{3}\right) . \mathrm{Gd}_{2} \mathrm{Zr}_{2} \mathrm{O}_{7}$ was also considered by Gatzen et al. (Ref 52). Another possible candidate is yttrium-aluminum-garnet $\left(\mathrm{Y}_{3} \mathrm{Al}_{5} \mathrm{O}_{12}-\mathrm{YAG}\right)$, as suggested by Weyant and Faber (Ref 53). All these coatings were deposited via traditional APS; i.e., no assisted heating was employed.

So far, it seems that APS $\mathrm{Y}_{2} \mathrm{O}_{3}$ is one of the most "promising" candidate as an EBC for oxide-oxide CMCs. $\mathrm{Y}_{2} \mathrm{O}_{3}$ is a chemically and thermodynamically stable material with a melting temperature of $2425^{\circ} \mathrm{C}$. It exhibits a cubic structure $\left(\alpha-\mathrm{Y}_{2} \mathrm{O}_{3}\right)$ that is maintained until $\sim 2300{ }^{\circ} \mathrm{C}$, when it transforms into hexagonal. However, this temperature is beyond the limits of operation of oxideoxide CMCs. In addition, the CTE of $\mathrm{Y}_{2} \mathrm{O}_{3}$ is $\sim 9 \times 10^{-}$ ${ }^{6} /{ }^{\circ} \mathrm{C}$; which is similar to that of $\mathrm{Al}_{2} \mathrm{O}_{3}$ of oxide-oxide CMCs (i.e., $\sim 8 \times 10^{-6} /{ }^{\circ} \mathrm{C}$ ). Regarding its water vapor attack resistance, it is superior to that of $\mathrm{Al}_{2} \mathrm{O}_{3}$ (see Fig. 5 Gatzen et al. (Ref 44)). Finally, it does not have a tendency to form amorphous phases during spraying, like EBCs for SiC/SiC CMCs. However, Mechnich and Braue (Ref 10) 
observed the presence of a metastable monoclinic $\mathrm{Y}_{2} \mathrm{O}_{3}(\beta-$ $\mathrm{Y}_{2} \mathrm{O}_{3}$ ) as a minor secondary phase in the as-sprayed coating (within a major crystalline $\alpha-\mathrm{Y}_{2} \mathrm{O}_{3}$ phase); which was attributed to the rapid solidification rate of the sprayed particles. This phase completely transformed into $\alpha-\mathrm{Y}_{2} \mathrm{O}_{3}$ after a heat treatment at $1200{ }^{\circ} \mathrm{C}$ for $1 \mathrm{~h}$. On the contrary, Vaßen et al. (Ref 51) reported only the presence of the stable cubic $\alpha$-phase in the as-sprayed $\mathrm{Y}_{2} \mathrm{O}_{3}$ APS EBC (i.e., no metastable phases); which is the same result observed by the National Research Council of Canada (NRC) when spraying $\mathrm{Y}_{2} \mathrm{O}_{3}$ via APS (Metco 3MB torch $-\mathrm{N}_{2} / \mathrm{H}_{2}$ plasma) (Ref 54).

It is important to highlight that Mechnich and Braue (Ref 10) deposited the $\mathrm{Y}_{2} \mathrm{O}_{3} \mathrm{EBC}$ on $\mathrm{Al}_{2} \mathrm{O}_{3} / \mathrm{Al}_{2} \mathrm{O}_{3}$ CMCs, which typically consist of dense alumina fibers embedded in a porous alumina matrix. Due to this "complex structure", in order to improve the bond strength of the APS $\mathrm{Y}_{2} \mathrm{O}_{3} \mathrm{EBC}$ on the porous $\mathrm{CMC}, \mathrm{a} \sim 100-\mu \mathrm{m}$ thick reaction bonded $\mathrm{Al}_{2} \mathrm{O}_{3}$ (RBAO) bond coat was applied over the $\mathrm{CMC}$. The RBAO bond coat was "slurry-painted" over the $\mathrm{CMC}$ followed by a heat treatment in air at $1300{ }^{\circ} \mathrm{C}$ for 1 h. Subsequently the EBC/CMC system was subjected to a furnace cycle test (FCT) in air. Each cycle consisted of 50 min at $1200{ }^{\circ} \mathrm{C}$, followed by a 10 -min cooling to RT via pressurized air jets. The FCT evaluation was stopped after 500 cycles, since there was no macroscopic evidence of EBC spallation, which was confirmed by SEM analysis. A strong chemical bonding observed between the $\mathrm{Y}_{2} \mathrm{O}_{3}$ EBC and the RBAO bond coat (formation of yttrium aluminates) helped to explain the high stability of this system in thermal cycling. In spite of this promising result, this type of system needs to be thermally cycled in water vapor environment, as to be discussed later in this paper, in order to better evaluate the protection offered to the $\mathrm{CMC}$ by the EBC.

It needs to be stressed that Opila et al. (Ref 55) and Fritsch et al. (Ref 56) observed that the volatility of $\mathrm{Al}_{2} \mathrm{O}_{3}$ via $\mathrm{Al}(\mathrm{OH})_{3}$ gas formation in high temperature water vapor environment is not expected to be a problem below a temperature level of $1300{ }^{\circ} \mathrm{C}$, even for long-term applications. Consequently, as porous oxide-oxide CMCs are not supposed to operate at temperatures higher than $1200{ }^{\circ} \mathrm{C}$, one may infer that the EBCs for oxide-oxide CMCs will be predominantly engineered to protect the CMCs against high temperature, CMAS attack and erosion. In other words, protection against water vapor attack will probably be of secondary importance. In fact, Lebel et al. (Ref 57) tested porous uncoated $\mathrm{Al}_{2} \mathrm{O}_{3} / \mathrm{Al}_{2} \mathrm{O}_{3} \mathrm{CMCs}$ in a laser-rig thermal gradient environment. Surface fibre buckling and delamination were observed on the surface of the uncoated CMC during laser-rig cycling. For this reason, it is hypothesised that an EBC could protect the CMC against these high-temperature damage effects.

\section{Processing and Manufacturing of EBCs by Other Thermal Spraying Techniques}

It is beyond the scope of this paper to discuss or expand how other thermal spraying techniques have been employed to deposit EBCs. Briefly, Harder et al. (Ref 58) employed the use of plasma spray physical vapor deposition (PS-PVD) to manufacture EBCs. PS-PVD bridges the gap between plasma spray and vapor phase methods. One of the great potential of this technique is related to the fact it is a non-line-of-sight deposition. Dense or columnar coating microstructures can be engineered. The initial results seem to be promising, i.e., isothermal exposure PSPVD $\mathrm{Yb}_{2} \mathrm{Si}_{2} \mathrm{O}_{7}$ EBCs to water vapor at $1316{ }^{\circ} \mathrm{C}$ for 500 hours shows little crystallographic change.

Bakan et al. (Ref 59) applied high velocity oxy-fuel (HVOF) to engineer $\mathrm{Yb}_{2} \mathrm{Si}_{2} \mathrm{O}_{7}$ EBCs. One of the great potential of the HVOF is related to the fact that it produced dense, and vertical crack-free EBCs, although the assprayed coatings were partially crystalline.

Bakan et al. (Ref 50) also attempted suspension plasma spray (SPS) and very low-pressure plasma spraying (VLPPS) $\mathrm{Yb}_{2} \mathrm{Si}_{2} \mathrm{O}_{7}$-based EBCs. The SPS EBC was predominantly amorphous, but few XRD peaks were identified and showed the presence of the stable and metastable phases of $\mathrm{Yb}_{2} \mathrm{SiO}_{5}$, as well as, $\mathrm{Yb}_{2} \mathrm{O}_{3}$. VLPPSbased EBCs was crystalline, showing the predominant presence of the $\mathrm{Yb}_{2} \mathrm{Si}_{2} \mathrm{O}_{7}$ as the main phase. The VLPPS result was attributed to the high temperatures reached during spraying $\left(980^{\circ} \mathrm{C}\right)$ and the controlled slow cooling after deposition.

The solution precursor plasma spray process (SPPS) was a route also pursued by Darthout et al. (Ref 60) and Chen et al (Ref 61). Highly crystalline as-sprayed EBCs were obtained by using this process.

\section{Foreign Object Damage (FOD) and Erosion of EBCs}

Gas turbine engines, mainly the aviation ones, are typically exposed to foreign objects, such as dust, volcanic ashes, sand, hail stones, sleet pellets, runway sand/gravel/debris and even birds. The impact of these objects into the turbine components can cause damage to the $\mathrm{EBC}$, which can lead from partial to nearly total EBC removal. The EBC removal can lead to (i) loss of turbine aerodynamic (airflow) performance (due to rough surfaces) and (ii) catastrophic structural damage (due to rapid unprotected component recession/corrosion in water vapor).

Bhatt et al. (Ref 62) studied the impact resistance, or foreign object damage (FOD) of APS EBCs deposited on $\mathrm{SiC} / \mathrm{SiC}$ CMCs. FOD occurs via externally ingested or 
internally generated debris. The APS EBC consisted of three layers: (i) a $\mathrm{Si}$ bond coat, (ii) a mullite+BSAS mixture interlayer and (iii) a BSAS top coat. Two totally distinct EBC thickness levels were manufactured: (i) 225 $\mu \mathrm{m}$ and (ii) $525 \mu \mathrm{m}$. Impact tests were performed with a gas gun that accelerated a single solid chrome-steel sphere $\left(\mathrm{HRC} \geq 60\right.$ - diameter $\sim 1.59 \mathrm{~mm}$ - density $7.8 \mathrm{~g} / \mathrm{cm}^{3}$ ) at velocities ranging from 110 to $400 \mathrm{~m} / \mathrm{s}$ onto the specimen surface at normal incidence. The impact tests were performed at RT and $1316{ }^{\circ} \mathrm{C}$ in air. Impacted samples were subsequently exposed at high temperature $\left(1316^{\circ} \mathrm{C}\right.$ for 500 h) in the presence of water vapor $\left(90 \% \mathrm{H}_{2} \mathrm{O}+10 \% \mathrm{O}_{2}\right)$. EBC spallation at the impact sites and the formation of cracks and internal oxidation of the CMC underneath the impacted sites were observed; whereas no silica growth was observed in the undamaged areas. This observation highlights the importance of maintaining EBC integrity against the impact of large particles. Moreover, the results suggest that "thin" EBCs are not effective in shielding substrate damage against large particles.

Okita et al. (Ref 63) tested the erosion resistance levels of APS EBCs deposited on SiC-SiC CMCs. The composition of the APS EBC layers was not revealed. The erodent material was fused and crushed silica particles, exhibiting an average particle size of $50 \mu \mathrm{m}$. The erosion test was performed in a hot wind tunnel $\left(1038{ }^{\circ} \mathrm{C}-225 \mathrm{~m} / \mathrm{s}\right)$ at different angles. According to Okita et al. (Ref 63), when comparing the EBC erosion rate values to those of with TBCs under similar test conditions, the averaged erosion rate of the APS EBC is much less than that of an APS TBC (about 1/6) and comparable to that of an EB-PVD TBC. The dependence of the impact angle is also similar to TBCs; i.e., erosion rate decreases as impingement angle decreases from $90^{\circ}$ for ceramic-based materials. These preliminary results show the promising potential of employing APS EBCs on gas turbine components, with respect to erosion performance against small particles.

\section{CMAS Attack on EBCs}

In addition to erosion, $\mathrm{EBC}$ removal can also occur via the calcium-magnesium alumino-silicate (CMAS) attack. CMAS attack occurs when foreign particulates (e.g., dust, airborne/runway sand and volcanic ash) are ingested with the intake air and are fully or partially melted in the combustion chamber and then subsequently deposited onto the EBC-coated components of the engine. The typical composition of these foreign particulates is based on a combination of $\mathrm{CaO}+\mathrm{MgO}+\mathrm{Al}_{2} \mathrm{O}_{3}+\mathrm{SiO}_{2}$; thereby the acronym CMAS. In other words, the combustion chamber acts as a flame-spray, whereas the foreign particulates act as powder feedstocks and the EBC-coated components of the engine act as the substrate. A glassy crust gets deposited on the EBCs when combustion temperatures adjacent to the coated-parts exceed $\sim 1200{ }^{\circ} \mathrm{C}$; which is the typical melting point range of CMAS materials. At temperature levels below this point, EBC erosion is then likely to occur. CMAS attack is a serious problem for EBCs. As previously stated, the persistent dash to increase the operating temperature of gas turbines is one of the key driving forces for the rising of EBCs and CMCs in the gas turbine industry.

The CMAS damage on EBCs can occur (i) mechanically or (ii) chemically. It occurs mechanically when the molten CMAS penetrates into the open pores and/or open vertical cracks of the EBC. Due to the EBC densification in the penetrated region (i.e., the pores/cracks get filled up with CMAS), the stiffness (i.e., elastic modulus) in that zone increases. For this reason, during heating and cooling stages, additional stresses arise in between the CMASpenetrated (dense) zone and the original non-penetrated porous one (located underneath). When the stress levels are higher than the fracture toughness of the EBC, spallation occurs; leaving the original non-penetrated porous zone open to the environment, leading to further CMAS penetration and EBC spallation. Additionally, differences in CTE values between the CMAS and EBC also are another source of stress during the heating and cooling stages, which can contribute to EBC cracking and spallation. This type of problem can be potentially addressed by manufacturing vertically crack-free, dense or porous, but gastight EBCs.

The chemical CMAS damage on EBCs occurs via thermally activated chemical reactions between the glassy CMAS deposits and the EBCs. These high-temperature chemical reactions can induce the formation of new phases on the EBC, with distinct CTE and/or stiffness levels or even the formation of phases that exhibit lower melting points that those of the original EBC. All these transformations and interactions induce additional stresses to the EBC/CMC systems, thereby leading to EBC spallation. As these reactions are of a chemical nature and thermally activated, this type of problem cannot be easily addressed, even by manufacturing vertically crack-free, dense or porous but gas-tight EBCs.

As an example, Ahlborg and $\mathrm{Zhu}$ (Ref 64) studied the CMAS attack on RE-silicate $\left(\mathrm{Yb}_{2} \mathrm{Si}_{2} \mathrm{O}_{7}\right.$ and $\left.\mathrm{Yb}_{2} \mathrm{SiO}_{5}\right)$ based EBCs at $1500{ }^{\circ} \mathrm{C}$. It was observed that the CMAS penetrated the EBCs preferentially at grain boundaries and dissolved the EBC material to form low-melting grain boundary pockets. After $200 \mathrm{~h}$ of testing, these low-melting phases extended through the entire thicknesses of the samples.

Zhao et al. (Ref 65) produced YbMS and YbDS-based APS EBCs and analyzed the CMAS attack at $1300{ }^{\circ} \mathrm{C}$. The samples were held at this temperature for varying times up 
to $200 \mathrm{~h}$. Exposure of both coatings to CMAS resulted in dissolution of both YbMS and YbDS topcoat. The overall CMAS attack mechanism was described as the dissolution of the silicate and re-precipitation as apatite, with some important differences in reaction morphology between YbMS and YbDS. Zhao et al. (Ref 65) concluded that in situations where the reaction rate is not controlled by the availability of silicate deposits, the reaction between CMAS and with $100 \mu$ m-thick YbMS or YbDS top coats is sufficiently aggressive at $1300{ }^{\circ} \mathrm{C}$ to seriously imperil the desired 5,000 to 10,000 h operational life of $\mathrm{SiC}$ composite components.

The study of Stolzenburg et al. (Ref 66) showed the same trend. The interaction of CMAS and $\mathrm{Yb}_{2} \mathrm{Si}_{2} \mathrm{O}_{7}$-based EBCs at $1300{ }^{\circ} \mathrm{C}$ led to changes in lattice spacing, alterations of the ambient temperature stresses and large cracks in the CMAS that extend through the topcoat. Moreover, Stolzenburg et al. (Ref 66) concluded that the best role for $\mathrm{Yb}_{2} \mathrm{Si}_{2} \mathrm{O}_{7}$-based material may be to serve as an EBC that is protected by an oxide thermal barrier coating (TBC); which would mitigate the CMAS interaction, thereby protecting the EBC against CMAS degradation.

For these reasons, the concept of thermal-environmental barrier coating (TEBC) may become imperative to address these CMAS degradation issues; i.e., a CMAS-resistance ceramic oxide layer needs to be deposited over the EBC system. Based on this idea, Lee et al. (Ref 67) investigated the possibility of using $\alpha$-alumina as a CMAS-resistance layer. Volcanic ash was employed as CMAS-based material. The reaction between $\alpha$-alumina (99.9\% pure) and volcanic ash was investigated using differential thermal analysis (DTA) and x-ray diffraction (XRD), from RT up to $1480{ }^{\circ} \mathrm{C}$. DTA was compared using individual (i) volcanic ash and (ii) $\alpha$-alumina+volcanic ash samples. The DTA results of the volcanic ash indicated a melting point of $\sim 1235{ }^{\circ} \mathrm{C}$. DTA pattern of the $\alpha$-alumina+volcanic ash mixture did not exhibit any sharp endothermic valley that could be associated with its melting temperature even at $1480{ }^{\circ} \mathrm{C}$. However, the onset of an endothermic region was observed starting from $1310^{\circ} \mathrm{C}$. Therefore, even if the melting partially started at $1310^{\circ} \mathrm{C}$, it was still higher than the original volcanic ash melting temperature of $1235^{\circ} \mathrm{C}$. Regarding this temperature, XRD results showed that $\alpha$ alumina+volcanic ash reacted at $\sim 1310{ }^{\circ} \mathrm{C}$, forming anorthite $\left(\mathrm{CaAl}_{2} \mathrm{Si}_{2} \mathrm{O}_{8}\right)$, magnetite $\left(\mathrm{Fe}_{3} \mathrm{O}_{4}\right)$ and spinel $\left(\mathrm{Al}_{1.75} \mathrm{Mg}_{0.889} \mathrm{Mn}_{0.351} \mathrm{O}_{4}\right)$ phases as reactive products. The melting points of magnetite, anorthite and spinel are $1538{ }^{\circ} \mathrm{C}, 1553{ }^{\circ} \mathrm{C}$ and $2135^{\circ} \mathrm{C}$; respectively. Consequently, according to Lee et al. (Ref 67), since these melting temperatures are now above the typical surface operating temperature levels of turbine components, the melting-induced penetration of volcanic ash and CMAS can be considerably suppressed.
On that account, it is hypothesized that a thermally sprayed alumina layer may act as the CMAS-resistant top coat for TEBC systems, including the ones designed to protect $\mathrm{SiC} / \mathrm{SiC}$ and ox-ox CMCs. But other factors need to be taken into account, which comprises (i) the CTE mismatch between that of alumina $\left(\sim 8 \times 10^{-6} /{ }^{\circ} \mathrm{C}\right)$ and those of EBC compositions, (ii) the tendency of the formation of metastable alumina phases $\left(\gamma-\mathrm{Al}_{2} \mathrm{O}_{3}\right)$ during thermal spraying and (iii) the water vapor attack resistance of alumina, anorthite, magnetite and spinel phases. It is known that gadolinium zirconate $\left(\mathrm{Gd}_{2} \mathrm{Zr}_{2} \mathrm{O}_{7}\right)$, which was designed for use as a TBC, exhibits "good" performance against CMAS infiltration. Consequently, it may be also a candidate as a CMAS-resistant top coat. However, its high CTE level $\left(\sim 11-12 \times 10^{-6} /{ }^{\circ} \mathrm{C}\right)$ could hinder its application in TEBC architectures. For all these reasons discussed in this manuscript, the CMAS attack resistance remains one of the most critical challenges in EBC R\&D.

\section{EBC/CMC Testing}

Table 3 lists various EBC test rigs and their capability. The total pressure, the water vapor pressure, and the gas velocity are the most critical variables for the EBC performance (see Eq. 3). The mass spectrometer and the steam TGA are useful tools for recession studies. The NASA high pressure mass spectrometer has been used to identify the volatile species during recession (Ref 68), the NASA lowpressure mass spectrometer has been used to determine the activity of volatile species (Ref 27,28 ), and the NASA steam TGA has been used to determine the volatility of candidate EBCs (Ref 26). Water vapor is the most critical species for the EBC oxidation, while the gas velocity does not appear to affect the EBC oxidation (Ref 21).

Steam cycling rigs, with a high $\mathrm{P}\left(\mathrm{H}_{2} \mathrm{O}\right)$ and a low gas velocity, are therefore ideal to study the long-term oxidation kinetics of EBCs at a fraction of the cost of burner rig testing. Steam jet rigs, with a high $\mathrm{P}\left(\mathrm{H}_{2} \mathrm{O}\right)$, a high gas velocity, and a small ( $\sim 1 \mathrm{~mm}$ ) steam-affected zone, have been used to study the recession (Ref 30). Laser-rigs are ideal for the thermal and thermo-mechanical fatigue test and the evolution of thermal conductivity with time. Many burner rigs combine a high $\mathrm{P}\left(\mathrm{H}_{2} \mathrm{O}\right)$ and a high gas velocity and therefore are ideal for both recession and oxidation studies.

Burner rigs in combination with special specimen fixtures are used to test the thermal or thermomechanical fatigue. NASA uses burner rigs equipped with a salt and a particle injector to test the molten salt corrosion and the erosion. Burner rigs equipped with a CMAS injector are used to study the CMAS degradation (Ref 69). Table 4 ranks the relative severity of $\mathrm{H}_{2} \mathrm{O}$ recession test rigs 
Table 3 List of various EBC test rigs and their capability.

\begin{tabular}{|c|c|c|c|c|c|}
\hline Rig & Location & $\begin{array}{l}P_{\text {total }} \\
(\mathrm{atm})\end{array}$ & $\begin{array}{c}P\left(\mathrm{H}_{2} \mathrm{O}\right) \\
\quad(\mathrm{atm})\end{array}$ & $\begin{array}{c}V(\mathrm{~m} / \\
\mathrm{s})\end{array}$ & Primary capability \\
\hline $\begin{array}{l}\text { Mass } \\
\text { Spectrometer }\end{array}$ & $\mathrm{NASA}^{\mathrm{a}}$ & N/A & N/A & $\mathrm{N} / \mathrm{A}$ & Recession \\
\hline Steam TGA & NASA & 1 & 0.5 & 0.1 & Recession \\
\hline \multirow[t]{2}{*}{ Steam cycling } & NASA & 1 & 0.9 & 0.1 & Oxidation \\
\hline & NRC (Canada) $)^{b}$ & 1 & $0.5-0.9$ & 0.025 & \\
\hline Steam jet & $\mathrm{UVA}^{\mathrm{c}}(\operatorname{Ref} 30)$ & 1 & 1 & 175 & Recession \\
\hline \multirow[t]{2}{*}{ Laser-Rig } & NASA & 1 & air & 0 & Thermal and thermo-mechanical fatigue, thermal conductivity \\
\hline & NRC (Canada) & 1 & air & 0 & \\
\hline \multicolumn{6}{|l|}{ Burner Rig } \\
\hline Jet fuel & NASA (Mach 0.3) & 1 & 0.1 & 100 & Molten salt corrosion, CMAS, erosion \\
\hline $\mathrm{CH}_{4}$ & NASA & 1 & 0.58 & 110 & Recession, oxidation, thermal and thermo-mechanical fatigue \\
\hline Jet fuel & NASA & 30 & 1.5 & 30 & Recession, oxidation, thermal and thermo-mechanical fatigue \\
\hline $\mathrm{CH}_{4}$ & Fraunhofer $^{\mathrm{d}}(\operatorname{Ref} 29,45,46)$ & 5 & 0.9 & 50 & Recession, oxidation \\
\hline $\mathrm{CH}_{4}$ & Julich $^{\mathrm{e}}$ (Ref 69) & 1 & 0.5 & 5 & Oxidation, CMAS, thermal fatigue \\
\hline $\mathrm{CH}_{4}$ & CRIEPI $^{\mathrm{f}}(\operatorname{Ref} 70)$ & 4 & 0.44 & 150 & Recession, oxidation \\
\hline
\end{tabular}

${ }^{a}$ NASA Glenn Research Center, Cleveland, OH, USA

${ }^{b}$ National Research Council of Canada, Boucherville, QC, Canada

${ }^{\mathrm{c}}$ University of Virginia, Charlottesville, VA, USA

${ }^{\mathrm{d}}$ Fraunhofer, Dresden, Germany

${ }^{\mathrm{e}}$ Forschungszentrum, Julich, Germany

${ }^{\mathrm{f}}$ Central Research Institute of Electric Power Industry, Yokosuka, Kanagawa, Japan

Table 4 Parametric ranking of various rigs for $\mathrm{Si}(\mathrm{OH})_{4}$ flux and $\mathrm{SiC}$ mass loss.

\begin{tabular}{lccc}
\hline \multicolumn{1}{c}{ Rig } & $\mathrm{J}\left(\mathrm{Si}(\mathrm{OH})_{4}\right)$ (relative) & Hot zone dia. (mm) & Mass loss (relative) \\
\hline UVA-steam jet & 1 & 1 & 1 \\
NASA- $\mathrm{CH}_{4}-\mathrm{O}_{2}$ & 0.27 & 25 & 172 \\
NASA-jet fuel & 0.17 & 25 & 110 \\
NASA Mach 0.3-jet fuel & 0.01 & 25 & 27 \\
Fraunhofer- $\mathrm{CH}_{4}$ & 0.19 & 25 & 125 \\
Julich- $\mathrm{CH}_{4}$ & 0.04 & 25 & 5 \\
CRIEPI-jet fuel & 0.09 & 25 & 58 \\
\hline
\end{tabular}

calculated using Eq. 3 in conjunction with the values of $P_{\text {total }}, P\left(\mathrm{H}_{2} \mathrm{O}\right)$, and $V$ from Table 1 (Ref 70). Mass loss is the most commonly used metric to determine recession rates. One-inch diameter hot zone was assumed for the calculation of the mass loss for burner rigs. Steam jet rig has the highest volatility per unit area, however, the small steam-affected zone $(\sim 1 \mathrm{~mm})$ limits the mass loss. The NASA natural gas burner rig has the highest mass loss, followed by the Fraunhofer, and the NASA high-pressure burner rig. High-pressure and high-velocity burner rigs are expensive to run, however, they simulate the actual gas turbine environments most closely. They are, therefore, most ideal for validation tests of mature EBCs and high
TRL (technology readiness level) subcomponent and component tests prior to engine tests.

\section{Recent Successes of EBC/CMC Application in Jet Turbines}

It needs to be pointed out that commercial jet turbines have started to use EBCs/CMCs at some of the core parts of the hot-section (e.g., combustion chamber, nozzles and shrouds). According to Steibel (Ref 71), EBC/CMC R\&D has enabled the commercial introduction of CMC highpressure turbine shrouds in the CFM International (GE Aviation + Safran Aircraft Engines joint venture) LEAP 
engine; which was certified by the Federal Aviation Authority and European Aviation Safety Agency (EASA) in May of 2016. In 2019, the CMC shrouds have surpassed four million hours of flight time in commercial LEAP engines flying on Airbus (A320neo), Boeing (737 MAX) and COMAC (C919) aircraft (Ref 71).

The general electric (GE) GE9X engine employs ceramic matrix composite (CMC) inner and outer combustor liners, HPT stage 1 and stage 2 nozzles and HPT stage 1 shrouds; which are protected by EBCs (Ref 71). According to the Guinness Book of Records, the GE9X turbine engine, which GE Aviation developed for Boeing's new $777 \mathrm{X}$ aircraft, reached $60,000 \mathrm{kgf}(134,000 \mathrm{lbf})$ of thrust during a test run in 2017 (Ref 72). Consequently, Guinness World Records Certified the GE9X as the world's most powerful jet engine in 2019 (Ref 72). At the highest performance, $\mathrm{EBC} / \mathrm{CMC}$ parts for this engine can operate at near $1300{ }^{\circ} \mathrm{C}$, at the same time requiring less cooling air, while allowing more air into the mixer (i.e., combustion). The additional air in the mixer helps reduce emissions by creating a leaner burn (Ref 72, 73). Moreover, the GE9X exhibits a fuel burn improvement of $10 \%$ when compared to its predecessor engine GE90-115B (Ref 74). Finally, it is important to highlight that the Boeing 777X powered by the GE9X engines took its $1^{\text {st }}$ flight on January 25 (2020) (Ref 75).

\section{Conclusions}

The EBC/CMC systems will be a paramount technology for enabling the manufacturing of ceramic-based gas turbines for aerospace applications. The driving force behind this technology is found on the non-stoppable demand for more efficient and environmentally friendly propulsion and energy generation systems. EBCs/CMCs will allow turbines to reach power levels not attainable today, by allowing them to operate at higher combustion temperatures simply not achievable by the current technology; at the same time emitting lower pollutant levels than those of state-of-the-art gas turbines. Finally, due to the fact that CMCs exhibit lower density levels than those of Ni-based metallic super-alloys, the combination of higher power levels and lower total mass will result in gas turbines exhibiting superior thrust-to-weight ratios totally unmatched by the current technology. Although perspectives are amazing, there are still many challenges toward transferring this technology to the industry. The key challenges are typically associated with the complexity to engineer EBCs via thermal spraying and the interactions of EBC materials at high temperature with the environment of a gas turbine engine (e.g., water vapor oxidation, water vapor corrosion, phase stability, erosion and CMAS attack), as well as, thermal cycling. The very first commercial jet engines using EBC/CMC technology in the turbine core are already flying. Consequently, the possibilities for future R\&D initiatives and projects are immense.

\section{References}

1. I. Spitsberg and J. Steibel, Thermal and Environmental Barrier Coatings for $\mathrm{SiC} / \mathrm{SiC} \mathrm{CMCs}$ in Aircraft Engine Application, Int. J. Appl. Ceram. Technol., 2004, 1(4), p 291-301.

2. N.P. Padture, Advanced Structural Ceramics in Aerospace Propulsion, Nat. Mater., 2016, 15, p 804-809.

3. A.G. Evans and D.B. Marshall, The Mechanical Behavior of Ceramic Matrix Composites, Acta Metall., 1989, 37(10), p 2567-2583.

4. J.A. Dever, M.V. Nathal and J.A. DiCarlo, Research on HighTemperature Aerospace Materials at NASA Glenn Research Center, J. Aerosp. Eng., 2013, 26(2), p 500-514.

5. E.J. Opila, J.L. Smialek, R.C. Robinson, D.S. Fox and N.S. Jacobson, $\mathrm{SiC}$ Recession Caused by $\mathrm{SiO}_{2}$ Scale Volatility under Combustion Conditions: II, Thermodynamics and Gaseous-diffusion Model, J. Am. Ceram. Soc., 1999, 82(7), p 1826-1834.

6. W. Braue and P. Mechnich, Tailoring Protective Coatings for Alloxide Ceramic Matrix Composites in High Temperature/High Heat Flux Environments and Corrosive Media, Mater. Sci. Eng. Technol. (Materialwissenschaft und Werkstofftechnik), 2007, 38(9), p 690-697.

7. K.N. Lee, D.S. Fox, J.I. Eldridge, D. Zhu, R.C. Robinson, N.P. Bansal and R.A. Miller, Upper Temperature Limit of Environmental Barrier Coatings Based on Mullite and BSAS, J. Am. Ceram. Soc., 2003, 86(8), p 1299-1306.

8. Y. Xu, X. Hu, F. Xu and K. Li, Rare Earth Silicate Environmental Barrier Coatings: Present Status and Prospective, Ceram. Int., 2017, 43, p 5847-5855.

9. U. Steinhauser, W. Braue, J. Goring, B. Kanka and H. Schneider, A New Concept for Thermal Protection of All-mullite composites in Combustion Chambers, J. Eur. Ceram. Soc., 2000, 20, p 651-658.

10. P. Mechnich and W. Braue, Air Plasma-sprayed $\mathrm{Y}_{2} \mathrm{O}_{3}$ Coatings for $\mathrm{Al}_{2} \mathrm{O}_{3} / \mathrm{Al}_{2} \mathrm{O}_{3}$ Ceramic Matrix Composites, J. Eur. Ceram. Soc., 2013, 33, p 2645-2653.

11. D.R. Clarke, M. Oechsner and N.P. Padture, Thermal-Barrier Coatings for More Efficient Gas-Turbine Engines, MRS Bull., 2012, 37(10), p 891-898.

12. S. Farokhi, Aircraft Propulsion-2nd Edition, Wiley, Chichester, 2015, p 8-9

13. J.H. Perepezko, The Hotter the Engine the Better, Science, 2009, 326, p 1068-1069.

14. A.H. Lefebvre and D.R. Ballal, Gas Turbine Combustion-Alternative Fuels and Emissions, $3^{\text {rd }}$ Edition Edition, CRC Press, Boca Raton, 2010, p 91-92

15. Rolls-Royce-The Jet Engine, Renault Printing Co Ltd, Birmingham, 1996, p 35-37

16. T. Bhatia, D. Jarmon, J. Shi, S. Kearney, A. Kojovic, J. Hu and A. Prociw, CMC Combustor Liner Demonstration in a Small Helicopter Engine, in Proceedings of ASME TurboExpo 2010: Power for Land, Sea and Air, paper \#GT2010-23810, p 509-513. https:// doi.org/10.1115/GT2010-23810

17. G. Leonard and J. Stegmaier, Development of an Aeroderivative Gas Turbine Dry Low Emissions Combustion System, J. Eng. Gas Turbines Power, 1994, 116, p 542-546. 
18. http://www.acare4europe.org/sria/flightpath-2050-goals/protect ing-environment-and-energy-supply-0 (February 16, 2018)

19. https://www.gpo.gov/fdsys/pkg/FR-2012-06-18/pdf/2012-13828. pdf (February 16, 2018)

20. https://www.safran-aircraft-engines.com/commercial-engines/sin gle-aisle-commercial-jets/leap/leap-1b (February 16, 2018)

21. K.N. Lee, $\mathrm{Yb}_{2} \mathrm{Si}_{2} \mathrm{O}_{7}$ Environmental Barrier Coatings with Reduced Bond Coat Oxidation Rates Via Chemical Modifications for Long Life, J. Am. Ceram. Soc., 2019, 102(3), p 1507-1521.

22. K.N. Lee, Current Status of Environmental Barrier Coatings for Si-Based Ceramics, Surf. Coat. Technol., 2000, 133-134, p 1-7.

23. K.N. Lee, J.I. Eldridge and R.C. Robinson, Residual Stresses and Their Effects on the Durability of Environmental Barrier Coatings for SiC Ceramics, J. Am. Ceram. Soc., 2005, 88(12), p 3483-3488.

24. E.J. Opila and R. Hann, Paralinear Oxidation of CVD SiC in Water Vapor, J. Am. Ceram. Soc., 1997, 80(1), p 197-205.

25. K.N. Lee, Environmental barrier coatings for CMCs, Ceramic Matrix Composites. N.P. Bansal, J. Lamon Ed., Wiley, New York, 2015, p 430-451

26. K.N. Lee, D.S. Fox and N.P. Bansal, Rare Earth Silicate Environmental Barrier Coatings for $\mathrm{SiC} / \mathrm{SiC}$ Composites and $\mathrm{Si}_{3} \mathrm{~N}_{4}$ Ceramics, J. Eur. Ceram. Soc., 2005, 25, p 1705-1715.

27. N.S. Jacobson, Silica Activity Measurements in the $\mathrm{Y}_{2} \mathrm{O}_{3}-\mathrm{SiO}_{2}$ System and Applications to Modeling of Coating Volatility, $J$. Am. Ceram. Soc., 2014, 97, p 1959-1965.

28. G.C.C. Costa and N.S. Jacobson, Mass Spectrometric Measurements of the Silica Activity in the $\mathrm{Yb}_{2} \mathrm{O}_{3}-\mathrm{SiO}_{2}$ System and Implications to Assess the Degradation of Silicate-Based Coatings in Combustion Environments, J. Eur. Ceram. Soc., 2015, 35, p 4259-4267.

29. M. Fritsch, H. Klemm, The water vapor hot gas corrosion behavior of $\mathrm{Al}_{2} \mathrm{O}_{3}-\mathrm{Y}_{2} \mathrm{O}_{3}$ materials, $\mathrm{Y}_{2} \mathrm{SiO}_{5}$ and $\mathrm{Y}_{3} \mathrm{Al}_{5} \mathrm{O}_{12}$-coated alumina in a combustion environment, in The 30th Int. Conf. \& Exp. On Adv. Ceram. \& Composites. Cocoa Beach, FL; January 2006.

30. R.A. Golden, K. Mueller and E.J. Opila, Thermochemical Stability of Y2Si2O7 in High-Temperature Water Vapor, J. Am. Ceram. Soc., 2020, 103(8), p 4517-4535.

31. B.E. Deal and A.S. Grove, General Relationship for the Thermal Oxidation of Silicon, J. Appl. Phys., 1965, 36(12), p 3770-3778.

32. E.J. Opila, Variation of the Oxidation Rate of Silicon Carbide with Water-Vapor Pressure, J. Am. Ceram. Soc., 1999, 82(3), p 625-636.

33. B.T. Richards, K.A. Young, F. de Franqueville, S. Sehr, M.R. Begley and H.N.G. Wadley, Response of Ytterbium DisilicateSilicon Environmental Barrier Coatings to Thermal Cycling in Water Vapor, Acta Mater., 2016, 106, p 1-14.

34. K.N. Lee and M. van Roode, Environmental Barrier Coatings Enhance Performance of $\mathrm{SiC} / \mathrm{SiC}$ Ceramic Matrix Composites, Am. Ceram. Soc. Bulletin, 2019, 98(3), p 46-53.

35. K. Grant, S. Kramer, J. Lofvander and C. Levi, CMAS Degradation of Environmental Barrier Coatings, Surf. Coat. Technol., 2007, 202, p 653-657.

36. K. Grant, S. Kramer, G. Seward and C. Levi, Calcium-Magnesium-Silicate Interaction with Yttrium Monosilicate Environmental Barrier Coatings, J. Am. Ceram. Soc., 2010, 93(10), p 3504-3511.

37. J. Harder, J. Ramirez-Rico, J.D. Almer, K.N. Lee and K.T. Faber, Chemical and Mechanical Consequences of Environmental Barrier Coating Exposure to Calcium-Magnesium-Aluminosilicate, J. Am. Ceram. Soc., 2011, 94(S1), p S178-S185.

38. F. Stolzenburg, M.T. Johnson, K.N. Lee, N.S. Jacobson and K.T. Faber, The Interaction of Calcium-Magnesium-Aluminum-Silicate with Ytterbium Silicate Environmental Barrier Materials, Surf. Coat. Technol., 2015, 284, p 44-50.
39. N.P. Padture, Environmental Degradation of High-Temperature Protective Coatings for Ceramic-Matrix Composites in GasTurbine Engines. NPJ Mater. Degrad. 11 (2019).

40. K.N. Lee, H. Fritze and Y. Ogura, Progress in Ceramic Gas Turbine Development, Vol 2, M. van Roode, M. Ferber, D.W. Richerson Ed., ASME Press, New York, 2003, p 641-664

41. K.N. Lee, R.A. Miller and N.S. Jacobson, New generation of Plasma-Sprayed Mullite Coatings on Silicon-Carbide, J. Am. Ceram. Soc., 1995, 78(3), p 705-710.

42. G.S. Corman, Melt Infiltrated Ceramic Matrix Composites for Shrouds and Combustor Liners of Advanced Industrial Gas Turbines. Advanced Materials for Advance Industrial Gas Turbines (AMAIGT) Program Final Report. U.S. Department of Energy Cooperative Agreement DE-FC26-00CH11047, December 2010.

43. W.G. Mao, J.P. Jiang, Y.C. Zhou and C. Luc, Effects of Substrate Curvature Radius, Deposition Temperature and Coating Thickness on the Residual Stress Field of Cylindrical Thermal Barrier Coatings, Surf. Coat. Technol., 2011, 205, p 3093-3102.

44. C. Gatzen, D.E. Mack, O. Guillon and R. Vaßen, $\mathrm{YAlO}_{3}$-A Novel Environmental Barrier Coating for $\mathrm{Al}_{2} \mathrm{O}_{3} / \mathrm{Al}_{2} \mathrm{O}_{3}$-Ceramic Matrix Composites, Coatings, 2019, 9, p 609.

45. M. Fritsch, Heißgaskorrosion Keramischer Werkstffe in $\mathrm{H}_{2} \mathrm{O}$ Haltigen RauchgasatmosphärenO-Haltigen Rauchgasatmosphären, Fraunhofer IRB Verlag, TU Dresden, Dresden, 2007.

46. M. Fritsch, H. Klemm, M. Herrmann, A. Michaelis and B. Schenk, The Water Vapour Hot Gas Corrosion of Ceramic Materials, Ceram. Forum Int., 2010, 87, p 11-12.

47. B.T. Richards, H. Zhao and H.N.G. Wadley, Structure, Composition, and Defect Control During Plasma Spray Deposition of Ytterbium Silicate Coatings, J. Mater. Sci., 2015, 50, p 7939-7957.

48. E. Garcia, H. Lee and S. Sampath, Phase and Microstructure Evolution in Plasma Sprayed $\mathrm{Yb}_{2} \mathrm{Si}_{2} \mathrm{O}_{7}$ Coatings, J. Eur. Ceram. Soc., 2019, 39, p 1477-1486.

49. E. Bakan, Y.J. Sohn, W. Kunz, H. Klemm and R. Vaßen, Effect of Processing on High-Velocity Water Vapor Recession Behavior of Yb-Silicate Environmental Barrier Coatings, J. Eur. Ceramic Soc., 2019, 39, p 1507-1513.

50. E. Bakan et al., $\mathrm{Yb}_{2} \mathrm{Si}_{2} \mathrm{O}_{7}$ Environmental Barrier Coatings Deposited by Various Thermal Spray Techniques: A Preliminary Comparative Study, J. Therm. Spray. Tech., 2017, 26, p. 1011-1024.

51. R. Vaßen, E. Bakan, C. Gatzen, S. Kim, D.E. Mack and O. Guillon, Environmental Barrier Coatings Made by Different Thermal Spray Technologies, Coatings, 2019, 9, p 784. https:// doi.org/10.3390/coatings9120784

52. C. Gatzen, D.E. Mack, O. Guillon and R. Vaßen, Surface Roughening of A12O3/A12O3 Ceramic Matrix Composites by Nanosecond Laser Ablation Prior to Thermal Spraying, J. Laser Appl., 2019, 31, p 022018. https://doi.org/10.2351/1.5080546

53. C.M. Weyant and K.T. Faber, Processing-Microstructure Relationships for Plasma-Sprayed Yttrium Aluminum Garnet, Surf. Coat. Technol., 2008, 202, p 6081-6089.

54. R. S. Lima, APS Deposition of $\mathrm{Y}_{2} \mathrm{O}_{3}$ EBCs via the Metco $3 \mathrm{MB}$ APS Torch Using $\mathrm{N}_{2} / \mathrm{H}_{2}$ Plasma (NRC \# 190322B1), unpublished research.

55. E. J. Opila, N. S. Jacobson, D. L. Myers and E. H. Copland, Predicting Oxide Stability in High Temperature Water Vapor, J. Metals, January (2006) 22-28.

56. M. Fritsch, H. Klemm, M. Herrmann and B. Schenk, Corrosion of Selected Ceramic Materials in Hot Gas Environment, J. Eur. Ceram. Soc., 2006, 26, p 3557-3565.

57. L. Lebel, R. Boukhili and S. Turenne, Damage to an A-N720 Ceramic Matrix Composite Under Simulated Gas Turbine Static 
Component Conditions Using Laser Heating, J. Compos. Mater., 2018, 52(30), p 4127-4138.

58. B. J. Harder, D. Zhu, M. P. Schmitt and D. E. Wolfe, High Temperature Multilayer Environmental Barrier Coatings Deposited Via Plasma Spray-Physical Vapor Deposition, https://ntrs. nasa.gov/archive/nasa/casi.ntrs.nasa.gov/20150000326.pdf (June 1, 2020).

59. E. Bakan, G. Mauer, Y.H. Sohn, D. Koch and R. Vaßen, Application of High-Velocity Oxygen-Fuel (HVOF) Spraying to the Fabrication of Yb-Silicate Environmental Barrier Coatings, Coatings, 2017, 7, p 55. https://doi.org/10.3390/coatings7040055

60. E. Darthout, A. Quet, N. Brady and F. Gitzhofer, Lu2O3-SiO2$\mathrm{ZrO} 2$ Coatings for Environmental Barrier Application by Solution Precursor Plasma Spraying and Influence of Precursor Chemistry, J. Therm. Spray Technol., 2014, 23(3), p 325-332.

61. C. Jiang, D. Cietek, R. Kumar and E.H. Jordan, Ytterbium Silicate Environmental Barrier Coatings Deposited Using the Solution-Based Precursor Plasma Spray, J. Thermal Spray Technol., 2020 https://doi.org/10.1007/s11666-020-01046-1

62. R.T. Bhatt, S.R. Choi, L.M. Cosgriff, D.S. Fox and K.N. Lee, Impact Resistance of Environmental Barrier Coated $\mathrm{SiC} / \mathrm{SiC}$ Composites, Mater. Sci. Eng. A, 2008, 476, p 8-19.

63. Y. Okita, Y. Mizokami and J. Hasegawa, Experimental and Numerical Investigation of Environmental Barrier Coated Ceramic Matrix Composite Turbine Airfoil Erosion. J. Eng. Gas Turbines Power.

64. N.L. Ahlborg and D. Zhu, Calcium-Magnesium Aluminosilicate (CMAS) Reactions and Degradation Mechanisms of Advanced Environmental Barrier Coatings, Surf. Coat. Technol., 2013, 237, p 79-87.

65. H. Zhao, B.T. Richards, C.G. Levi and H.N.G. Wadley, Molten Silicate Reactions with Plasma Sprayed Ytterbium Silicate Coatings, Surf. Coat. Technol., 2016, 288, p 151-162.
66. F. Stolzenburg, P. Kenesei, J. Almer, K.N. Lee, M.T. Johnson and K.T. Faber, The Influence of Calcium-Magnesium-Aluminosilicate Deposits on Internal Stresses in $\mathrm{Yb}_{2} \mathrm{Si}_{2} \mathrm{O}_{7}$ Multilayer Environmental Barrier Coatings', Acta Mater., 2016, 105, p 189-198.

67. K.-I. Lee, L.T. Wu, R.T. Wub and P. Xiao, Mechanisms and Mitigation of Volcanic Ash Attack on Yttria Stablized Zirconia Thermal Barrier Coatings, Surf. Coat. Technol., 2014, 260, p 68-72.

68. D.L. Myers and N.S. Jacobson, Identification of Volatile Metal Hydroxides with Free Jet Expansion Sampling Mass Spectrometry, Calphad, 2019, 65, p 73-78.

69. T. Steinke, D. Sebold, D.E. Mack, R. Vaßen and D. Stöver, Novel Test Approach for Plasma-Sprayed Coatings Tested Simultaneously Under CMAS and Thermal Gradient Cycling Conditions, Surf. Coat. Technol., 2010, 205, p 2287-2295.

70. I. Yuri, T Hisamatsu, Recession rate prediction for ceramic materials in combustion gas flow, in Proceeding of SME Turbo Expo 2003 June 16-19, Atlanta, GA. CEPRI

71. J. Steibel, Ceramic Matrix Composites Taking Flight at GE Aviation, Am. Ceram. Soc. Bull., 2019, 98(3), p 30-33.

72. www.ge.com/reports/its-official-guinness-world-records-certi fies-ge9x-as-the-worlds-most-powerful-jet-engine/ (February 1, 2020)

73. www.geaviation.com/press-release/ge90-engine-family/ge9xsnew-taps-combustor-maintain-its-cool-under-fire (February 1, 2020)

74. https://www.aero-mag.com/ge-aviation-ge9x-boeing-777x/ (February 3,2020 )

75. https://www.boeing.com/commercial/777x/first-flight\#/overview (July 4, 2020)

Publisher's Note Springer Nature remains neutral with regard to jurisdictional claims in published maps and institutional affiliations. 